\title{
Preparing fertile ground: How does the business environment affect outcomes from microfinance?
}

\author{
Jonathan $\mathrm{Fu} \quad$ Annette Krauss \\ University of Zürich, Department of Banking and Finance*
}

February 5, 2020

\begin{abstract}
Entrepreneurial clients of microfinance providers are expected to invest in and grow their businesses, according to the standard claim of the financial inclusion industry. Yet, transformative effects on microfinance client business growth have largely been unrealized in most randomized controlled trial studies on microcredit. While these studies have been quite instructive, their broader policy relevance may be limited by their short timescales, localized geographic coverage, and invariance of business environments in which client businesses operate. In this paper, we draw on longer-term nationwide administrative data from a leading Cambodian financial service provider and exploit a quasi-natural experiment to test if and to what extent differences in business environments affect clients' business growth, when access to financial services is not a primary constraint. Our main finding is that positive district-level shocks to the business environment lead to increased employment in exposed client enterprises compared to client enterprises in contextually similar districts but who are unexposed. The effect is particularly strong for small (rather than micro) enterprises and clients located in districts with larger local economic markets. Finally, we pool data from past impact evaluations to demonstrate how a number of related business environment factors help explain heterogeneity found in their results. Policy implications are that microfinance clientele respond to opportunities provided by local business environments and that governments can play more active roles in improving business framework conditions.
\end{abstract}

Keywords: microfinance impact, enterprise growth, business environments, natural experiment

JEL Codes: G21, D22, O12, R1

\footnotetext{
*Acknowledgments: we would like to extend our gratitude to our research partner in Cambodia for providing access to their proprietary data and to participants of the UZH CSP quarterly research workshops and the 6th European Research Conference on Microfinance in Paris for helpful comments on the paper. Particular thanks go to Adriana Garcia, Julian Kölbel, Robert Lensink, and Steven Ongena for valuable suggestions on previous versions of this paper. Thanks also to Francis Cheneval, Christine Kauffman, Jahel Queralt, and Michele Romano for useful feedback during this ongoing research. Financial support from the Swiss National Science Foundation and the UZH Stiftung fur wissenschaftliche Forschung is also greatly appreciated. Corresponding author's contact: Jonathan.Fu@bf.uzh.ch, University of Zürich, Department of Banking and Finance, Center for Sustainable Finance and Private Wealth. Plattenstrasse 32, 8032 Zürich, Switzerland.
} 


\section{Introduction}

Financial inclusion refers to the delivery of basic formal financial services at affordable costs to disadvantaged and low-income segments of society. By the end of 2019, 72 national-level policymaking and regulatory bodies - predominantly from low-income countries - have made public commitments to financial inclusion strategies, policies, or targets (Alliance for Financial Inclusion, 2019). In part, this has been guided by a traditional theory of change emphasizing how increased financial inclusion - through microcredit and other adapted means - to unbanked or inadequately banked, low-income populations can lead to improvements to this market segment's productivity, income generation, and job creation via transformative effects on entrepreneurial activity (Levine, 2005).

This theory has become subject to vigorous debate and various points of critique. First, the contexts where financial inclusion is promoted tend to be characterized by pervasive informal sectors, where micro or small enterprises are generally unregistered, operated at the individual or household-level, and motivated by necessity as subsistence activities rather than driven by opportunities with high-growth potential (Bruhn, 2013). Second, a number of randomized controlled trials (RCTs) on microcredit provide fairly consistent evidence that average effects on entrepreneurial and poverty outcomes are fairly muted (Banerjee, Karlan, \& Zinman, 2015). However, they also document notable heterogeneity in business outcomes both across and within study contexts, with some authors noting most change to be occurring at either tails of the distribution (Deaton \& Cartwright, 2018). This has led a number of scholars to reopen the discussion on the scope and use or RCTs compared to other observational methods (Deaton \& Cartwright, 2018: Meager, 2019). Others have commented that capital constraints may not be the primary explanation for the weak outcomes for many microcredit clients and suggested that greater emphasis be placed on understanding the reasons for these differential effects (Banerjee, Duflo, et al., 2015, Beck, 2015; Pritchett \& Sandefur, 2015, Vivalt, 2020).

In particular, Banerjee (2013) suggests that a key constraint for many microcredit clients may instead be factors related to the quality of business environments in which typical clients operate. Despite the intuitive nature of the suggestion and its critical relevance to microcredit's theory of change, the empirical literature on microcredit has largely overlooked this in the past. This is perhaps due to difficulties either experimenting on broader business environments factors (which are typically beyond researchers control) or being able to capture both sufficient variation and a meaningful counterfactual group if drawing on observational data (as mentioned by Deaton \& Cartwright (2018); Meager (2019)). For example, given the many advantages of RCTs, they typically focus on average treatment effects from one-time interventions and tend to be restricted to smaller, localized client samples and/or studying shorter timescales given high implementation costs (Armendáriz \& Morduch, 2010, Wydick, 2016).

This study seeks to fill an evidence and research gap by answering the following main research question: "Does the quality of local business environments play a primary role in explaining enterprise growth outcomes of microcredit clients?" To do so, we exploit a natural experiment provided by the rollout of a number of localized Special Economic Zones (SEZs) in Cambodia that occurred between 2011 and 2016. The SEZs are subject to different laws and regulations from those pertaining to other areas of the country and are expected to lead to localized improvements to various "framework conditions". This includes improved administrative services, infrastructure, and local investment, among other advantages (Warr \& Menon, 2016). Some of the direct effects of 
the SEZs in Cambodia thus far include an estimated 70,000 waged jobs created - in mostly medium-sized export-orientated enterprises, over USD 2 billion in capital investment, and improvements to local infrastructure and institutions (Abonyi et al., 2016, Open Development Cambodia, 2017; Warr \& Menon, 2016).

However, an open question, on which the paper offers empirical evidence, concerns if and to what extent a positive localized shock to the business environment such as the advantages offered in an SEZ also benefits local and micro- and small enterprises. Building on endogenous growth and new institutional economic theories, theoretical literature on SEZs posit a number of expected dynamic effects. First, there may be "linkage effects", through which smaller domestic firms, both informal and formal, have increased opportunities to integrate into larger markets and SEZs can help drive productivity upgrading - for example, through transfers of human capital and technology (Baissac, 2011). Second, there may be "indirect spillover effects", where zones come to rely on their surrounding area for satisfaction of basic needs for accommodation, consumer services, and other place-specific non-zone activities (Baissac, 2011). More generally, local enterprises may also benefit from the expected improvements to local governance, infrastructure, and investment (Aggarwal, 2010; Baissac, 2011; Cheesman, 2012). However, empirical evidence of dynamic effects of SEZs on the business growth of local micro- and small enterprises is still quite limited.

We use data from several sources to empirically explore dynamic effects of SEZs as an example of a positive business environment shock, on the growth outcomes of microcredit clients. First, we obtain a unique proprietary data sample of entrepreneurial clients that is broadly representative of a major Cambodian financial service provider's micro- and small enterprise clients nationwide and covers the period from 2011 to 2016. These data include historical information on client, business, and loan characteristics, allowing us to track the borrowing relationship and business outcomes for clients throughout the study period. Second, we combine this with data on SEZs from Open Development Cambodia and contextual information on Cambodia's territorial administrative units from the Cambodian General Population Survey.

Using this merged data, we map the partner branches to SEZ locations at the districtlevel and apply propensity score weighting to construct a synthetic counterfactual group based on contextual characteristics known to drive SEZ placement. We then use these weights to combine "inverse probability of treatment weighting" (IPTW) and generalized difference-in-differences (DiD) methods for our main analysis. In other words, our identification strategy applies IPTW to better account for selection into treatment based on observables, and DiD to further account for selection on unobservables that are entity and time-invariant, conditional on relevant covariates from the extant literature.

Our main result is that we find evidence that SEZ implementation had a statistically and economically significant positive impact on employment growth among micro- and small enterprises that had access to finance. Specifically, we estimate that SEZ implementation increased employment growth in relative annualized terms by 16 percent between loan cycles for clients in SEZ districts with respect to clients in control districts. The main results are quite robust to model specifications and a variety of sensitivity checks, which also help indicate that benefits were not exclusive to a select SEZ or outlier clients. An alternative way of interpreting the economic magnitude of the effects on clients - which considers the average initial starting size of businesses of 1.7 employees - is that every 10 client businesses in the SEZ districts started out with approximately 17 employees combined and ended up with between 3 to 4 more additional employees combined compared 
to similar client businesses in the control districts, following SEZ implementation. Note that we are comparing outcomes for the subset of clients who had consecutive loan cycles more than a year apart.

We further test whether a number of client and district-level factors are shown to lead to differential effects. The client-level analyses indicate that employment growth driven by SEZ implementation appears to have been much more pronounced for small rather than microenterprise clients whether in absolute or relative terms, which suggests that the transformative potential of microcredit may indeed lie with the "missing middle". Meanwhile, they do not necessarily find stronger evidence of "linkage effects"vs. "indirect spillover effects", as proxied by testing for differential employment growth for production and trade vis-à-vis service sector businesses. Meanwhile, district-level analyses confirm that a number of SEZ and territorial characteristics drawn from literature moderate the intensity of the effect. In particular, we observe larger treatment effects for client businesses that are located in larger markets and cross-border districts, and more mature SEZs.

Finally, we pool data from a number of widely-cited microcredit studies and use our findings to explore how variation in business environments in these past studies contribute to explaining outcome heterogeneity in their results. This secondary analysis confirms the importance of a number of the aforementioned "framework conditions" in predicting differential client business outcomes. For example, we find particularly strong results for indicators capturing whether clients were in locations with better institutions and rule of law, access to larger local economic markets, and access to infrastructure.

Our paper contributes to literature strands on financial access and on enterprise growth. To the best of our knowledge, ours is the first empirical study in the financial access literature to explicitly focus on the role of contextual aspects of business environment in explaining the entrepreneurial outcomes of microcredit clientele. A study that is perhaps closest in underlying intuition is by Ashraf et al. (2009), who focus on the role of improved contextual opportunities through an experiment combining access to credit (for new export-orientated crop production) and improved value-chain linkages to new markets. They find that the joint interventions led to an increase in production of export-oriented crops and lower marketing costs, which ultimately translated into higher business profits and household income for new adopters, albeit the experiment eventually failed in the longer-run when the exporter ran into unrelated legal troubles. Most recently, Meager (2019) also pools data from past microcredit RCTs to explore whether heterogeneity in treatment effects across studies may be predicted or explained by variables defined at the "site-level" (that is, by study). However, her analysis primarily focuses on showing how differences in experimental protocol across studies explain outcomes, rather than explicitly exploring the role of country subregional business environment factors. Finally, there is also one prior quasi-experimental study on microcredit which uses a large-scale and phased branch expansion in Mexico as an identification strategy and finds heterogeneous effects for smaller compared to larger sized retailers (Cotler \& Woodruff, 2008). However, their study did not specifically explore how differences in the business environment context across the subnational regions might have influenced client outcomes.

With respect to the enterprise growth literature on business environments and SEZs, our paper is methodologically close to Steenbergen \& Javorcik (2017), who also focus on analyzing firm-level impacts from SEZs, and combine propensity score matching (PSM) and difference-in-differences to improve identification. However, their data sample consists of export-orientated medium-sized enterprises (with more than 30 employees) within SEZs 
who are more likely to fall in the category of static rather than dynamic effects. There are also several recent empirical studies on dynamic effects of SEZ conducted by Alkon $(2018)$; Ciżkowicz et al. (2016); Wang (2013). However, apart from Ciżkowicz et al. (2016), who study firm-level effects in the context of Poland, the remainder all study territorial-level outcomes. To the best of our knowledge, ours is thus the first study which attempts to estimate dynamic linkage and spillover effects on local micro- and small enterprise-level outcomes in a developing country context. Moreover, ours is only the second study after Frick et al. (2018), to empirically study how different SEZ and territorial factors may influence the intensity of dynamic effects, where we again differ in using enterprise-level outcomes. By contract, Frick et al. (2018) use territorial nightlight data as a more general proxy for capturing changes in economic activity.

Our results have several implications for policy. First and foremost, they help demonstrate that microfinance clientele can and do exhibit significantly increased business growth when the context of local business environments improve as well. Second, they suggest that national and local governments can and should play active roles in shaping the quality of these environments through combined or targeted interventions toward various framework conditions. Third, they support the idea that such policies are particularly conducive to helping small-sized enterprises - that is, the "missing middle" - to thrive. Finally, the study also highlights the utility of targeting and collaborating with appropriate financial service providers to facilitate cost-effective collection of broader business data on clients, in order to better understand other requisite contextual drivers of entrepreneurial outcomes in developing country contexts.

The remainder of the paper proceeds as follows. Section 2 reviews relevant literature on microfinance's impact and empirical literature on the role of business environment context and enterprise growth. Section 3 provides background on the Cambodian study context. Section 4 describes the study's data sources and the construction of treatment and control groups. Section 5 presents the paper's main empirical analysis and results. Section 6 discusses the broader relevance of our results in relation to prior microfinance impact evaluations. Finally, Section 7 concludes.

\section{Literature Review}

This paper draws on and contributes to three streams of the literature. Firstly, we contribute to the literature on entrepreneurial outcomes from microcredit. Secondly, the paper also contributes to a large body of literature on business environments from enterprise growth and institutional economic literature. Finally, our results also relate to the distinct literature on economic outcomes of Special Economic Zones.

\subsection{Microcredit \& Entrepreneurial Outcomes}

Recent discourse on the impact of microcredit has been most heavily influenced by results from a number of RCTs. Banerjee, Karlan, \& Zinman (2015, p. 1) summarize the combined results from six widely cited RCTs on microcredit as indicating "modestly positive, but not transformative, effects" on the average client, noting the general consistency of this finding despite variation in aspects of loan product design, targeted clients, providers, and country settings in the studies. Based on a more comprehensive critical review of the broader impact literature on microcredit, Beck (2015, p. 20) adds that "[a] conclusion 
would be that effects are typically statistically and economically more significant for individual or household level outcomes than on the microenterprise level". ${ }^{1}$

Despite this high-level takeaway, the RCT results and other impact evaluations also document considerable heterogeneity in business outcomes both within and across studies. First, as noted by Banerjee, Karlan, \& Zinman (2015) and Pritchett \& Sandefur (2015), their focus on average treatment effects masks evidence that some clients in certain studies do exhibit transformative business outcomes. For example, Banerjee, Duflo, et al. (2015) undertake the longest-term study, considering the effect of a randomized branch expansion program of an MFI in Hyderabad, and find that three years later businesses in the treatment areas are larger, but the effect is concentrated among a few highly successful clients with pre-existing businesses. Second, it is worth highlighting that across studies, some find evidence in line with the original idea of microcredit supporting or improving entrepreneurship, whereas others do not. For example, Augsburg et al. (2015) and Attanasio et al. (2015) report increases in levels of enterprise creation and profits among Bosnian and Mongolian microfinance clients, respectively, and Angelucci et al. (2015) find some positive effects on enterprise size, but of only a small economic magnitude. Bruhn \& Love (2014) exploit a unique "natural experiment" in which over 800 bank branches opened simultaneously in pre-existing locations of a Mexican retailer and find a sizeable effect on informal enterprise creation or continuation, especially among low-income individuals and those located in areas with lower pre-existing bank penetration. A study by Tarozzi et al. (2015), however, detects no significant effects on business profits, entry, or exit and a study by Karlan \& Zinman (2011) actually observes that expanded microcredit led to decreased profits and business size for clients of an MFI in the Philippines, in part attributed by the authors to diversion of entrepreneurial finance for household purposes. (See Appendix Table D.1 for a summary of the study contexts and business outcomes for key studies.)

As previously, Banerjee, Duflo, et al. (2015) ultimately conclude by noting that some micro- and small entrepreneurs might not be as credit constrained as commonly assumed and/or that other, additional factors might actually be more binding constraints. As such, impact research has shifted toward identifying and better understanding additional factors that explain differential effects of credit. Many scholars have naturally focused on individual or business-level factors. A number of studies have documented high rates of lifestyle and subsistence entrepreneurs as opposed to growth-orientated entrepreneurs in many developing and emerging economies, which leads to expectations that most business transformation (or decline) will indeed occur within a small subset of growth-orientated microfinance clients. For example, studies in India (Hsieh \& Klenow, 2009) and Mexico (Bruhn, 2013) estimate that anywhere from 50 to 90 percent of microenterprises exhibit characteristics similar to those of wage workers, and have no plans to grow or expand. In this context, Beck (2015) mentions that the archetypical practice of microcredit targeting a female clientele might actually restrain it from having maximum impact in terms of business growth, since female borrowers are more likely to have to combine household duties with entrepreneurial activity.

A related extension seen both among practitioners and in impact research has consequently been the promotion of "microcredit plus", where loan products are coupled with other interventions, such as financial education or business/agricultural skills and management training. These are intended to alleviate individual and business-level factors seen as posing additional constraints, such as low financial literacy or poor business management skills. Here too the evidence has been somewhat mixed. For example, 
Karlan et al. (2015) and Karlan \& Valdivia (2011) conduct RCTs in urban Ghana and Peru, combining access to finance with consulting or entrepreneurial training, but find no evidence of improved business revenue, profits, or employment. De Mel et al. (2014), meanwhile, do find that combined business training and grant money for a group of female entrepreneurs increase short-term profitability for existing entrepreneurs and longer-term profitability for first-time entrepreneurs.

Meanwhile, while broader contextual features faced by the microcredit clientele may intuitively play important roles in constraining individuals' opportunities and motivations for business growth, these have tended to be mostly overlooked in the related empirical literature on financial access. Given the important advantages of RCTs, other scholars have noted that the high cost and practical difficulties of implementing them means that they tend to be fairly localized and are typically limited to studying shorter-term (1-to-2 year) impacts of single interventions (Armendáriz \& Morduch, 2010) or rely on identifying narrow subsets of clients on the margins (Wydick, 2016). ${ }^{2}$ This arguably makes them less useful for evaluating how other broader factors, such as the local business environment context, may affect client business outcomes, even though Banerjee (2013) proposes that these may actually pose greater constraints. We therefore start by postulating a proposition that guides this paper's analysis:

- Proposition: Microfinance client growth is conditional on opportunities provided by local business environments.

To the best of our knowledge, the study in this literature stream that gets closest to testing a similar intuition is that of Ashraf et al. (2009), which evaluates the effects of combined access to credit with value-chain linkages for Kenyan smallholder farmers.

\subsection{Local Business Environment \& Special Economic Zones}

The empirical literature on enterprise growth and broader development has explored factors related to the local business environment more closely, including the role of subnational contexts, territorial dimensions, and quality of institutions.

Regarding the first of these, a common argument and the basic intuition being tested is that while high-growth firms can be found anywhere, certain areas provide greater opportunities and better environments for growth. Several scholars have focused on territorial aspects and documented that higher-growth firms are disproportionately concentrated in urban areas and areas with higher population density more generally (Acs \& Mueller, 2008). Stam (2009) highlights various advantages stemming from higher population density areas, including the relative ease of access to markets and customers as well as the inputs required (for example, capital, labour/employees, suppliers) to produce the goods or services. Moreover, a number of scholars have focused on the role of agglomerations - for example, industrial districts, local manufacturing systems of large firms, and technological districts - which are expected to lead to a number of "agglomeration effects", including improved integration into larger and external markets, reduced costs of input, and productivity spillovers (Audretsch, 2012, Porter, 1998). A number of scholars have demonstrated some of these territorial effects empirically (Audretsch, 2012; Giner et al., 2016). However, it is worth noting that the enterprise growth literature has so far focused primarily on formal enterprises located predominantly in developed or emerging economy contexts. It is possible that differences in economic structures (for example, size of the informal vis-à-vis formal economy and primary sectors of activity) and positioning of labour markets 
(for example, lower urbanization rates) in developing economies may shift the relative advantages for business growth toward different geographic areas.

In parallel, the literature of new institutional economics has long emphasized that it is local institutions which ultimately dictate whether entrepreneurial activity is allocated to productive, unproductive, or destructive purposes within a given economy (Acemoglu et al., 2014 Baumol, 1996, North, 1991). The implications for policymakers are that establishing conducive framework conditions can be a more effective way to prepare a fertile ground for winners to pick themselves. A growing body of evidence documents that the quality of the business environment-including such factors as governance (including efficiency of government administration, business regulation, and the rule of law), infrastructure, and access to markets - can notably differ at subnational-levels and have an important influence on the nature of entrepreneurial activity (Bjørnskov \& Foss, 2016, Hallward-Driemeier et al., 2006; Malesky, 2009).

Finally, a related but nonetheless distinct body of literature has developed around Special Economic Zones (SEZs), corresponding to their rapid global proliferation. ${ }^{3}$ SEZs are defined as demarcated geographic areas contained within a country's national boundaries where the rules of business are different from those that prevail in the national territory (Farole, 2011). These differential rules principally deal with investment conditions, international trade and customs, taxation, and the regulatory environment; whereby the zone is given a business environment that is intended to be more liberal from a policy perspective and more effective from an administrative perspective than that of the national territory. In short, they are expected to help catalyze the aforementioned framework conditions in particular subnational regions.

SEZs have generated a growing body of theoretical literature that highlights main economic or political goals and expected outcomes. As summarized by Farole (2011), expected outcomes of SEZs are commonly separated into static versus dynamic effects. Static effects include attracting foreign direct investment, increased foreign exchange earnings, and direct employment generation. Meanwhile, theories on dynamic effects posit that SEZs may create further catalytic effects within the surrounding domestic areas via linkages and spillovers (Aggarwal, 2010; Cheesman, 2012) - for example, through technological transfers, human capital upgrading (Johansson \& Nilsson, 1997), cultivation of value-chain linkages (Baissac, 2011), and greater local wealth.

Prior empirical studies on the links between SEZs and macro- or micro-level economic growth have generally provided stronger evidence of static effects but have been fairly limited with respect to dynamic effects. Until quite recently, most of the evidence on dynamic effects has come from case studies on SEZs, a few of which have provided some suggestive evidence of positive spillover effects on domestic enterprises and evidence of forward or backward linkages in a number of settings, such as India (Cheesman, 2012), Malaysia and Laos P.D.R. (Abonyi et al., 2016). ${ }^{4}$ While still limited in number, there are some recent empirical studies that provide more direct causal evidence of dynamic effects, albeit they thus far indicate stronger evidence of linkage rather than spillover effects. ${ }^{5}$ Wang (2013) uses a generalized difference-in-differences approach to demonstrate positive dynamic impacts of Chinese SEZs on local municipal economies neighboring SEZs, as measured by domestic investment, TFP growth, and local factor prices. Similarly, Ciżkowicz et al. (2016) apply fixed effects models to a merged firm and district-level panel dataset from Poland and find that SEZs have substantial positive effects on employment, for both the SEZ firms and outside firms in the host and neighboring counties. Finally, Alkon (2018) combines an original subdistrict-level dataset on Indian SEZs and census 
data and creates a synthetic control group using propensity score matching. By contrast, he finds that that the Indian SEZs have generally experienced insignificant "spillover" effects on local socioeconomic development, as proxied by a variety of district-level social and economic developmental variables, such as education and transport infrastructure, and percentage of marginalized households.

Building on this body of enterprise growth and SEZ literature, we develop our main hypothesis and several secondary hypotheses related to client-level factors that may interact with SEZ implementation to drive differential effects:

- $H_{1}$ : The implementation of SEZs as a means to improve the business environment has positive effects on the business growth of microcredit clients in these zones.

- $\mathrm{H}_{2} a$ : The implementation of SEZs has stronger effects on small enterprises vis-à-vis microenterprises.

- $\mathrm{H}_{2} b$ : The implementation of SEZs has stronger "linkage effects" than "spillover effects" on client businesses, as proxied by a positive differential in employment growth for trade and production vis-à-vis service sector enterprises.

- $\mathrm{H}_{2}$ c: The implementation of SEZs has stronger effects on more mature businesses, as roughly proxied by intensive margin vis-à-vis extensive margin business clients.

Finally, as highlighted by a recent study by Frick et al. (2018), despite the proliferation of SEZs, there has been virtually no quantitative research on what drives their dynamism. They posit that various factors related to the business environment context (including access to markets, human capital, and population density) and SEZ characteristics (including maturity, size, public or private operators, industry focus, infrastructure, and services offered) will have an important influence on the intensity of the dynamic effects from SEZs. Testing these factors on a purpose-built dataset on SEZs and night-light data, the strongest evidence they find concerns the importance of zone size and locations in close proximity to larger cities or markets.

We draw on these insights to similarly test whether a number of these factors interact with SEZ implementation in our setting to drive differential effects in client employment growth. This allows us to contribute additional evidence to this growing body of literature by exploring whether their general findings hold when looking at a more specific enterpriselevel outcome, as well as provide insights into further transmission mechanisms. Specifically, we test the following additional secondary hypotheses:

- $H_{3} a$ : There is a positive differential in employment growth for clients in larger economic markets, as proxied by being located in areas with higher population density.

- $H_{3} b$ : There is a positive differential in employment growth for clients in areas more conducive to trade, as proxied by being located in a country border vis-à-vis an interior area.

- $H_{3} c$ : There is a positive differential in employment growth for more mature SEZs.

- $H_{3} d$ : There is a positive differential in employment growth for SEZs in closer proximity to clients.

A summary of the basic theory of change guiding the paper's analysis is provided in Figure 1 below. 


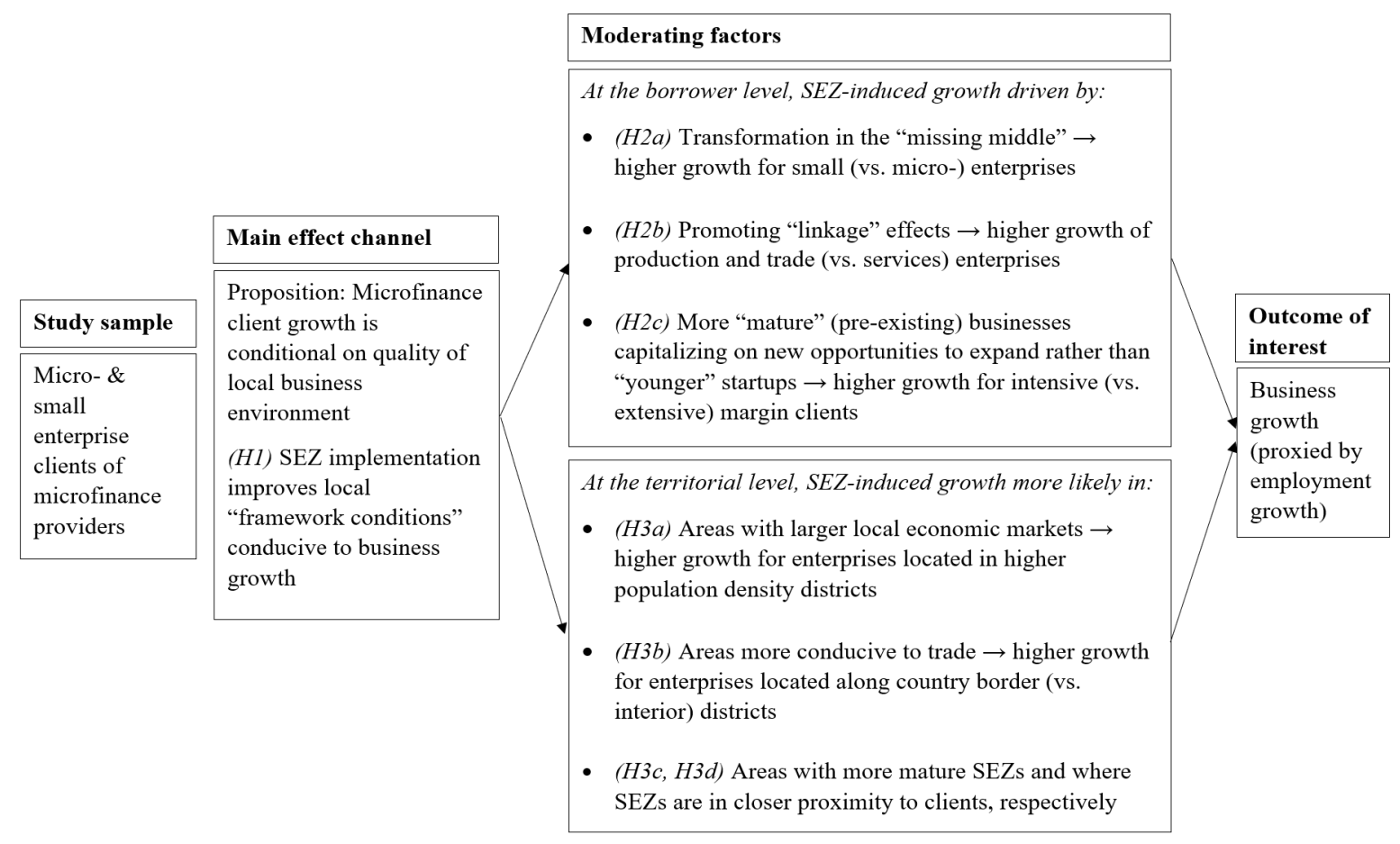

Figure 1: This figure provides an overview of the theory of change guiding this paper's analysis. We start with a sample of entrepreneurial clients of a microcredit provider (that is, those who are able to access formal credit). We expect SEZ implementation will improve the quality of local institutions, infrastructure, levels of investment, and other framework conditions conducive to enterprise growth. We further expect certain client types and territorial characteristics to have more opportunities to capitalize on these improvements, leading to differential treatment effects. 


\section{Study Context}

Cambodia is, during our study period, ideal for analyzing the role of subnational business environments in micro- and small enterprise growth, and for several reasons.

First, Cambodia's economy exhibited general growth and stability at the macro level, which has provided opportunities for both agricultural and nonagricultural businesses. Since early in the new millennium, and apart from a sharp but brief crisis period in 2008, ${ }^{6}$ Cambodia's economic growth has been among the fastest in Asia, with gross domestic product (GDP) growth averaging 7.9 percent from 2000 to 2016 (World Bank, 2019). During this period, its economy also benefited from general price stability, with inflation averaging 3.12 percent - excluding the crisis year in 2008, and minimal exchange rate fluctuation between the Cambodian riel and the US dollar. This generated social welfare improvements, with an estimated fall in the poverty rate from 50.2 to 17.7 percent between 2003 and 2012 (World Bank, 2019). This was driven by increases in agricultural prices, wages, and production and by higher incomes and wealth accumulation from self-employment in nonagricultural businesses (Asian Development Bank, 2016).

Second, financial inclusion and access to credit have reached high levels for the country's development status, allowing us to focus on other constraints to businesses. Domestic credit provided by financial institutions relative to GDP rose from roughly 6 to 71 percent from 2000 to 2016, and rates of borrowing from formal institutions reached 27 done in 2017 (World Bank, 2019). This has been coupled with high market penetration (Martinez \& Krauss, 2015), with microfinance providers and some leading commercial banks having greatly expanded access to poorer and rural populations. For example, in 2015, Cambodia's 34 microfinance institutions and seven micro-deposit institutions accelerated their credit growth to 46 percent year-on-year and reached a record high of USD 2.9 billion in outstanding loans to over two million borrowers, compared with USD 426 million and 0.9 million borrowers at the end of 2010 Asian Development Bank, 2016, 27). Our research partner is well situated, as it is one of the market leaders in terms of clients served and volume of savings and loans, has nearly nationwide outreach with branches in the majority of Cambodia's 25 provinces and 165 districts, and has a diverse lending portfolio covering micro- through medium-sized enterprises.

Third, development remains uneven across regions and households, with a weak overall business environment cited as a leading barrier to greater growth and opportunities. In 2012, over 90 percent of nonagricultural enterprises in the country were still estimated to be in the informal sector (World Bank, 2019) — typically, smaller-scale household run activities. Rural and informal enterprises are disproportionately affected by weak public service delivery, limited or lack of access to organized markets, and poor infrastructure, which are thought to be key constraints on their opportunities for growth (Hill \& Menon, 2013). For these reasons, while there have been some general improvements over the past several years, relevant surveys of local entrepreneurs highlight that the overall business environment in Cambodia is still quite poor, albeit with notable heterogeneity across provinces (Malesky, 2009).

Finally, the implementation of Cambodia's Special Economic Zones (SEZs) provides a useful natural experiment to test whether enterprises have responded to local business environment improvements. Cambodia's government set up a special legal form in 2005 allowing private operators to establish SEZs to help address uneven regional growth and development (Abonyi et al., 2016). From 2005 to 2016, 34 SEZs were set up in different districts and years (Open Development Cambodia, 2017) (see Appendix Table C.1 for a 
full list). The Cambodian government envisions them as comprising of production and manufacturing areas, as well as areas for services and residence, and owners are required to set up local infrastructure to meet minimum standards - that is to say, road networks, electricity, sewage treatment, water, and telecommunications. Since SEZs are often importor export-processing areas, they tend to be located in areas with access to deep-sea ports, near borders with neighboring countries, or where trade is facilitated by existing transport links - so, for example, near the main routes of the Greater Mekong Subregion economic corridors (Abonyi et al., 2016).

Prior case studies have found that Cambodia's SEZs have been modestly successful in providing high-quality waged employment and attracting foreign investment, ${ }^{7}$ and play useful roles as enclaves that provide a stable business environment, reasonable infrastructure, and less red tape (Abonyi et al., 2016). Warr \& Menon (2016) estimate around 70,000 waged jobs created in SEZ-located firms as of 2015. ${ }^{8}$ Furthermore, firms located within the SEZs tend to be more diversified than in the rest of Cambodia (where garment manufacturing dominates), which provides opportunities for forward-backward linkages (Warr \& Menon, 2016). Nevertheless, it is important to acknowledge that some of the listed SEZs are still not operational and earlier firm surveys conducted in select SEZs have found limited backward linkages to the domestic economy or opportunities for worker skill upgrading, as well as dissatisfaction with infrastructure and implementation of tax privileges for some firms (Warr \& Menon, 2016). Thus, the broader extent to which the SEZs have benefited local small and microenterprises remains an open question.

\section{Data}

The study's main objective is to ascertain if and to what extent differences in the quality of subnational business environments affect the business growth of microcredit clients when access to financial services is not a primary constraint. We use the staggered implementation of Cambodian SEZs as localized shocks to test whether there was higher employment growth for "treated" micro- and small entrepreneurs (that is, those in SEZ locations) compared to "control" entrepreneurs (that is, those in non-SEZ locations, with otherwise similar contextual characteristics). This requires data on individual entrepreneurs with large geographic and temporal coverage, as well as contextual information on SEZs and Cambodian districts.

\subsection{Data on Cambodian enterprises}

To obtain data on local enterprises, we worked with a leading Cambodian financial service provider to extract a stratified random sample of business loan client records from their management information system (MIS). ${ }^{9}$ The sample is broadly representative of their micro- and small enterprise clientele between the period of January 2011 to December $2016 .^{10}$

The MIS' various modules capture key information on clients, business, and loan characteristics. Importantly, the information for MIS variables are updated by loan officers and recorded at the initiation of every loan cycle for a client, allowing changes in key business growth indicators to be tracked across time.

We use data from the business module to construct the paper's main dependent variable, which is growth in number of employees between loan cycles. ${ }^{11}$ Drawing on lessons from empirical enterprise growth literature, we measure this both in terms of 
absolute and the relative (logarithmic) change ${ }^{12}$ and attempt to reduce statistical noise by requiring a minimum gap between loans of 12 months and normalizing the data into annualized growth rates. ${ }^{13}$ As summarized by Davidsson et al. (2010), methodological choices related to these factors have been shown to have an important influence on results. For example, different enterprises may be highlighted as being high-growth firms depending on the choices made for each. This implies a need to directly address them in empirical models or to run sensitivity checks to analyze how each separate methodology issue affects results.

The data also allow us to control for a variety of client and business-level characteristics drawn from relevant literature, which are cited as leading to differential effects on client outcomes. At the client-level, this includes the client's gender (Banerjee, Duflo, et al., 2015, McKenzie et al., 2008), age (Fajnzylber et al., 2006), whether they are an individual household or have dependents, and whether they have a single business activity or are simultaneously managing multiple activities (Demirgüç-Kunt et al., 2017). At the businesslevel, this includes whether the business is a micro or small enterprise (Mead \& Liedholm, 1998), the economic sector of the business (Coad, 2009), and the loan cycle number, which we use to separate between extensive or intensive margin clients, and also more loosely as a proxy for whether the business is at an earlier or later stage in its life cycle (Klapper \& Richmond, 2011).

Details on the data and construction of variables used for the study's main analysis are provided in Appendix B.

\subsection{Data on Cambodia's Special Economic Zones and Districts}

Data on Cambodia's Special Economic Zones and administrative areas are drawn respectively from the Open Development Cambodia website and the Cambodian General Population Census.

Open Development Cambodia maintains an SEZ database ${ }^{14}$ that provides an up-todate list of SEZs, their respective start dates, address, ownership, amount of initial capital investment, and land area. We use this information to map the SEZ locations to our research partner's branches at the district-level and construct a dummy variable at the district- and yearly-level for the date of a given SEZ's implementation. This dummy variable, which indicates the interaction between treatment group and post-treatment period, is used as the main explanatory variable in this paper's empirical analysis.

Information on Cambodia's administrative territories is drawn from the Cambodian General Population Census, which was conducted by Cambodia's National Institute of Statistics in $1998^{15}$ and $2008^{16}$ (with a partial inter-censal census in 2013). We use these census data to compile information on population size, land area, population density, and population growth. We similarly map these data at the district-level to the SEZs and our research partner's branches in order to analyze the contextual background of districts that are included in our study sample.

We choose to use districts as the territorial level for separating branch clients into treatment and control groups for the paper's analysis because it mirrors the branchstructure of our research partner, which typically has one branch office per district. ${ }^{17}$ The few exceptions where there are more than one branch per district are in the three main urban agglomerations in Cambodia-Phnom Penh, Siem Reap, and Battambang, where the population density is high enough in a few instances to support more than one branch within a single district. 
Of the 126 branches of our research partner in the full data sample, twenty branches are located in districts where an SEZ has been implemented. Among these, nine branches are in locations where the SEZ was implemented during the paper's study period - that is, between January 1st, 2011 and December 31st, 2016 - and the SEZ is the first ever to be implemented in the district. It is worth specifying that we decide to use all twenty branches and districts where SEZs were implemented for estimating propensity scores for SEZ implementation since it helps improve precision of the model. However, to avoid the possibility of confounding effects on business outcomes from previous SEZs, clients from branches located in districts with SEZs implemented before 2011 are omitted in the later difference-in-differences analysis on employment growth. ${ }^{18}$ A list of Cambodian SEZs and details on which are included in our main analysis is provided in Appendix Table C.1.

An important takeaway from Table C.1 is that there is both geographical and temporal variation in the implementation of the SEZs during the study period, which our main analysis exploits for its empirical strategy. A limitation worth acknowledging, however, is that the dates of implementation for two of the SEZs included in the paper's main analysis are toward the end of the study period. To the extent that the effects of SEZ implementation on business growth are lagged, this may lead to underestimated results.

\subsection{Establishing treatment and control groups}

The study's "treatment" group are thus micro- and small business loan clients from nine of our research partner's branches located in districts where an SEZ was implemented for the first time between 2011 and 2016 .

As described in Sections 2.2 and 3 , the placement of SEZs - both in Cambodia and more generally - tends to follow some established patterns (that is, it is non-random). This may lead to concern that different ex-ante contextual characteristics of the SEZ districts bias estimates from the paper's main analysis. To mitigate these concerns, we use propensity score weighting to create a synthetic control group that mimics key contextual factors that are expected to influence likelihood of SEZ location, based on the literature discussed previously or demonstrated through exploratory analyses of our data. We run a probit regression at the branch-district level to obtain propensity scores - estimates of the probability of SEZ placement-based on a district's land area, population density, and dummy indicators for whether a district is an urban location, situated on country or ocean borders, along the Greater Mekong Subregion economic corridor, and broader country region. Table 1 summarizes main results from the propensity score regression. The model's $c h i^{2}$ value confirms that we can reject the null hypothesis that the included variables do not jointly explain SEZ implementation. Meanwhile, the pseudo- $R^{2}$ indicate that the model regressors explain roughly $30 \%$ of the probability of SEZ implementation.

We draw on these district-level propensity scores in our subsequent empirical analysis through the application of inverse propensity of treatment weighting (IPTW). In brief, inverse probability weighting tries to make counter-factual inference more prominent by using the propensity scores to overweight or underweight observations to create a quasi-experimental framework. The underlying intuition is that treatment observations with a high-probability to receive treatment and which do receive treatment provide less useful counterfactual information and are thus given relatively lower weight in calculate of average treatment effects. Conversely, observations which have a low-probability to receive treatment but end up receiving treatment are unusual and therefore more informative of how treatment would affect subjects with low probability of receiving it - that is, 
characteristics mostly associated with control subjects. Therefore, they are given greater weight. Following the same idea, if a control subject has a large probability of receiving treatment it is an informative indicator of how subjects in the treatment would behave if they were in the control group and thus greater weight is placed on unlikely and highly-informative control subjects. In practice, the calculation of IPTW is defined as below:

$$
w(x)=\frac{Z}{e}+\frac{(1-Z)}{(1-e)}
$$

where $Z$ denotes treatment status and $e$ denotes a district's propensity score.

A key advantage of IPTW over propensity score matching methods is that it foregoes the common support (or overlap) conditions that are applied in propensity score matching methods. ${ }^{19}$ By allowing use of all observations in the control and treatment groups for outcome estimation, IPTW methods are better able to maintain statistical power to detect a treatment effect (Caliendo \& Kopeinig, 2008).

Figures 2 and 3 provide a visual depiction of the resultant propensity scores and inverse propensity for treatment scores for each district where our partner institution has branches. Branch districts numbered with an SEZ constitute our treatment group and the remaining branch districts constitute the pool for our synthetic control group. There are three takeaways. First, we can see that the SEZ districts tend to be clustered around country border areas or along the Greater Mekong Subregion (GMS) economic corridor. Second, we can observe that there are a few SEZ districts which had relatively low propensity based on their characteristics and, conversely, several non-SEZ districts that have high propensity for treatment. Finally, we can see that these latter treatment and control districts tend to be those that have particularly high inverse propensity scores.

Table 1: Propensity score model estimating predicted probability of SEZ placement based on district-level features

This table presents coefficient estimates for a probit model estimating the predicted probability of SEZ placement based on district-level contextual features. The full sample includes 126 branches-districts, of which 20 are SEZ district locations.

\begin{tabular}{|c|c|c|c|c|c|c|}
\hline \multicolumn{4}{|l|}{ Probit regression } & \multirow{3}{*}{$\begin{array}{l}\text { \# of obs. } \\
\text { LR chi }{ }^{2}(10) \\
\text { Prob > } \text { chi }^{2} \\
\text { Pseudo } \text { R }^{2}\end{array}$} & \multirow{3}{*}{$\begin{array}{l}= \\
= \\
= \\
=\end{array}$} & \multirow{3}{*}{$\begin{array}{c}126 \\
31.78 \\
0.0004 \\
0.280\end{array}$} \\
\hline & & & & & & \\
\hline Log likelihood & $=$ & -40.714 & & & & \\
\hline $\mathrm{DV}=\mathrm{SEZ}$ & Coef. & Std.Err. & $\mathrm{z}$ & $\mathrm{P}>\mathrm{z}$ & \multicolumn{2}{|c|}{$[95 \% \mathrm{CI}]$} \\
\hline Urban $=1$ & 0.06 & 0.46 & 0.12 & 0.90 & -0.84 & 0.95 \\
\hline Ln Land Area & 1.28 & 0.98 & 1.31 & 0.19 & -0.63 & 3.20 \\
\hline Ln Land Area Sq. & -0.08 & 0.09 & -0.87 & 0.39 & -0.25 & 0.10 \\
\hline Ln Pop. Density & 0.15 & 0.32 & 0.47 & 0.64 & -0.47 & 0.77 \\
\hline \% Small enterprises & 0.58 & 0.55 & 1.06 & 0.29 & -0.50 & 1.66 \\
\hline GMS corridor $=1$ & 0.26 & 0.34 & 0.76 & 0.45 & -0.41 & 0.93 \\
\hline Border $=1$ & 1.34 & 0.42 & 3.17 & 0.00 & 0.51 & 2.17 \\
\hline North West Region & -1.11 & 0.63 & -1.77 & 0.08 & -2.34 & 0.12 \\
\hline East \& Mekong Plain region & -0.25 & 0.43 & -0.57 & 0.57 & -1.09 & 0.60 \\
\hline Special region (Phnom Penh agglom.) & 1.27 & 0.51 & 2.47 & 0.01 & 0.26 & 2.28 \\
\hline Constant & -8.03 & 4.15 & -1.93 & 0.05 & -16.16 & 0.11 \\
\hline
\end{tabular}




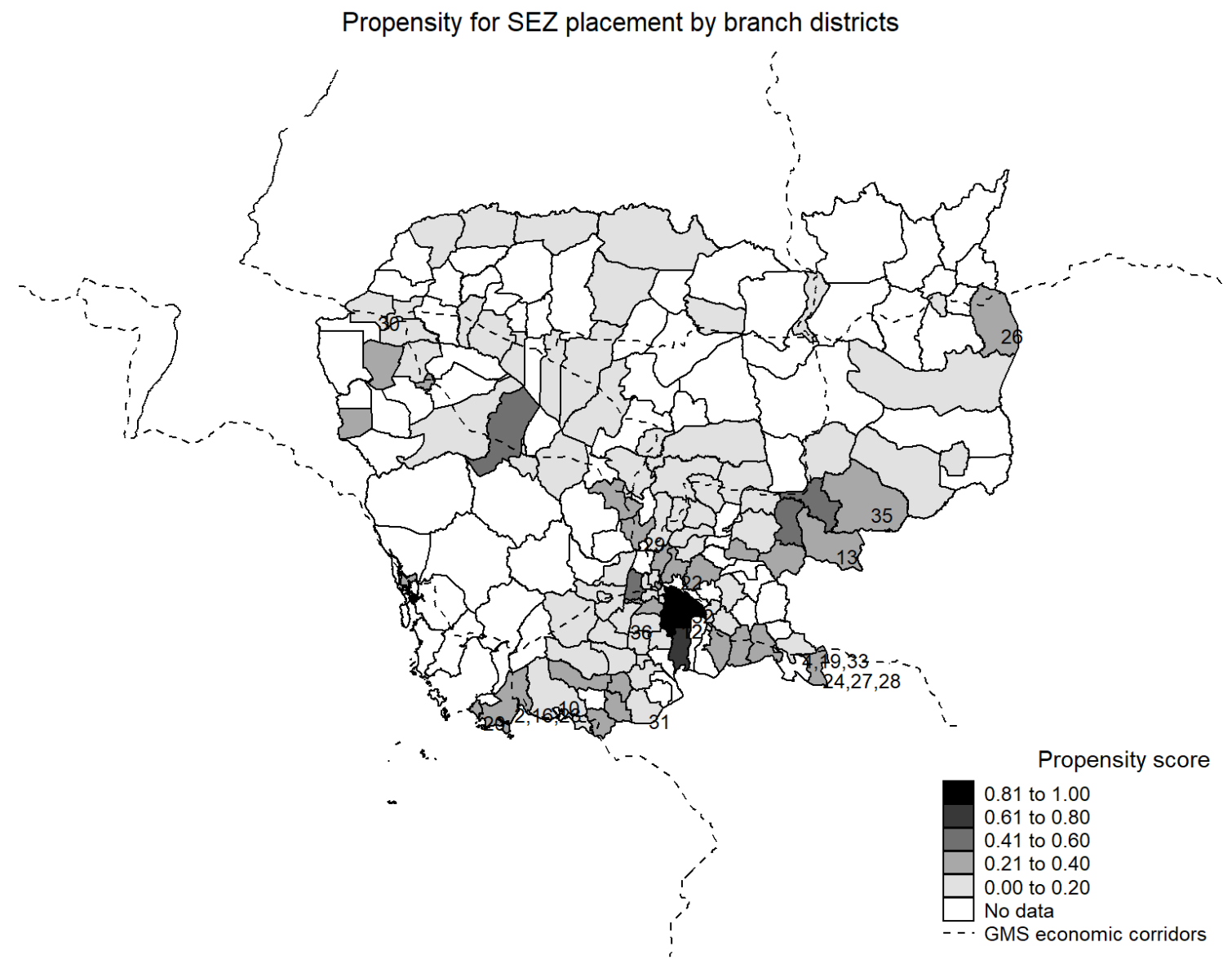

Figure 2: This figure depicts propensity for SEZ placement among Cambodian districts where our research partner had branches. Treatment districts with SEZs are numbered (see Appendix C.1 for details). Propensity scores are estimated using a probit regression at the branch-district level based on land area, population density, and dummy indicators for whether a district is an urban location, situated on country or ocean borders, along the Greater Mekong Subregion economic corridor, and broader country region.

We perform a series of tests in line with Caliendo \& Kopeinig (2008) and Imbens \& Rubin (2015) to check the appropriateness of our propensity score weighting and for meaningful differences between the established treatment and synthetic control groups.

First, we conduct an omnibus test of joint orthogonality to test for balance of our district-level contextual features after IPTW (Caliendo \& Kopeinig, 2008). Specifically, after estimating propensity scores for treatment for each district where our provider had branches, we construct inverse probability treatment weights and re-estimate the same probit regression as before with the weights applied. We compare the pseudo- $R^{2}$ 's and $\chi^{2}$ statistics before and after weighting. After IPTW, there should be limited systematic differences in the distribution of covariates between both groups and therefore, the pseudo$R^{2}$ should be fairly low. Furthermore, one can also compare the likelihood ratio chi-square on the joint significance of models regressors. The test should not be rejected before, and should be rejected after matching. Comparing our post-match regression results in Table 2 with our pre-match results in Table 1, we observe that the pseudo- $R^{2}$ roughly halves and that whereas we previously rejected the null hypothesis of no joint significance in the pre-match results based on the $\chi^{2}$ value, we can no longer do so after the weighing.

Second, we test for meaningful differences in client- and loan-level characteristics between our treatment and synthetic control groups. In line with Imbens \& Rubin (2015), 


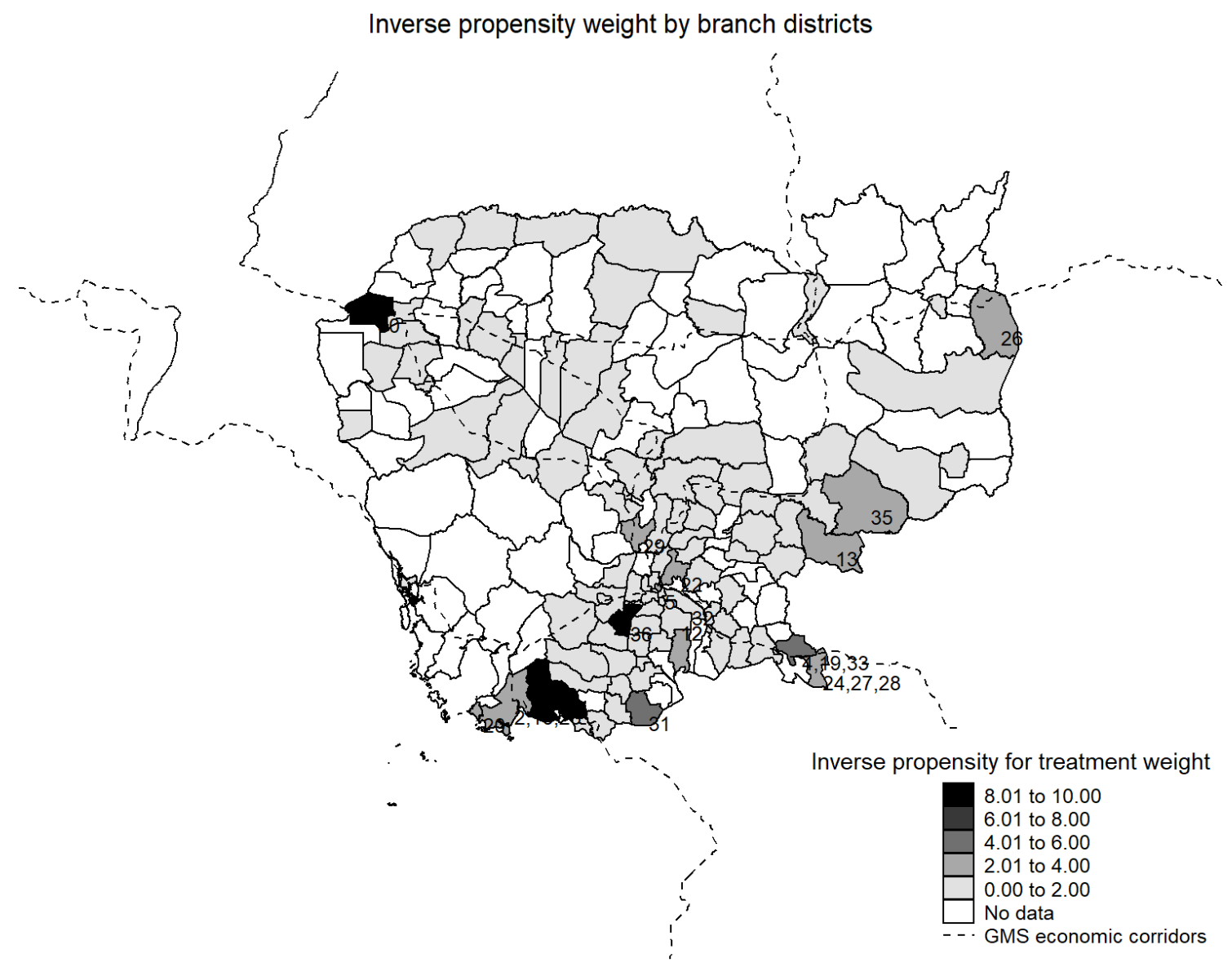

Figure 3: This figure depicts inverse propensity for treatment weights (IPTW) among Cambodian districts where our research partner had branches. Treatment districts with SEZs are numbered (see Appendix C.1 for details).

we adopt a standardized differences approach and focus on assessing the size of the differences in mean rather than their statistical significance. "Standardized differences" are defined as the difference in means for a given variable between treatment and control groups, divided by the standard deviation of the population from which the groups were sampled. ${ }^{20}$ As Imbens \& Rubin (2015) highlight, this approach provides a scale-invariant measure of the size of mean differences and they use this with propensity-score matching to demonstrate that differences of 1 or more are problematic in terms of giving results similar to an experiment, while differences of 0.25 or less are indicative of good balance. ${ }^{21}$ Table 3 Panels A and B summarize results from this investigation and illustrate that the client- and loan-level characteristics are generally well under this suggested threshold. There are some indications that the mean semester of loan applications were slightly later for the treatment group (the economic magnitude would equate to roughly 1.8 months), which supports controlling for time period in later regression models. However, we interpret the overall results as supporting the suitability of the propensity score model and the IPTW method for constructing viable synthetic comparison groups for our main analysis. Furthermore, to mitigate any potential remaining concerns over imbalance, we start of our empirical analysis by running event study models to formally test whether patterns of business growth between the treatment and control branches showed signs of significant divergence in the pre-treatment period-i.e., whether the parallel trends assumption appears to hold. 


\section{Table 2: Balance test on district-level factors and SEZ implementation}

This table presents coefficient estimates from a joint test of orthogonality to test for balance of district-level contextual features. We regress our district-level contextual variables on the treatment (SEZ) dummy variable and test for their joint significance. After applying inverse probability weights, there should be no systematic differences in the distribution of covariates between both groups and therefore, the pseudo-R2 should be fairly low (relative to the pre-weighting estimates). Furthermore, one can also compare the likelihood ratio chi-square on the joint significance of models regressors. The test should not be rejected before, and should be rejected after matching. We estimate propensity scores for both SEZ and non-SEZ branch districts on district-level contextual factors driving "treatment"-i.e., placement of SEZs. We then apply inverse probability of treatment weighting to create synthetic counterfactual groups for the DiD estimation. Robust standard errors.

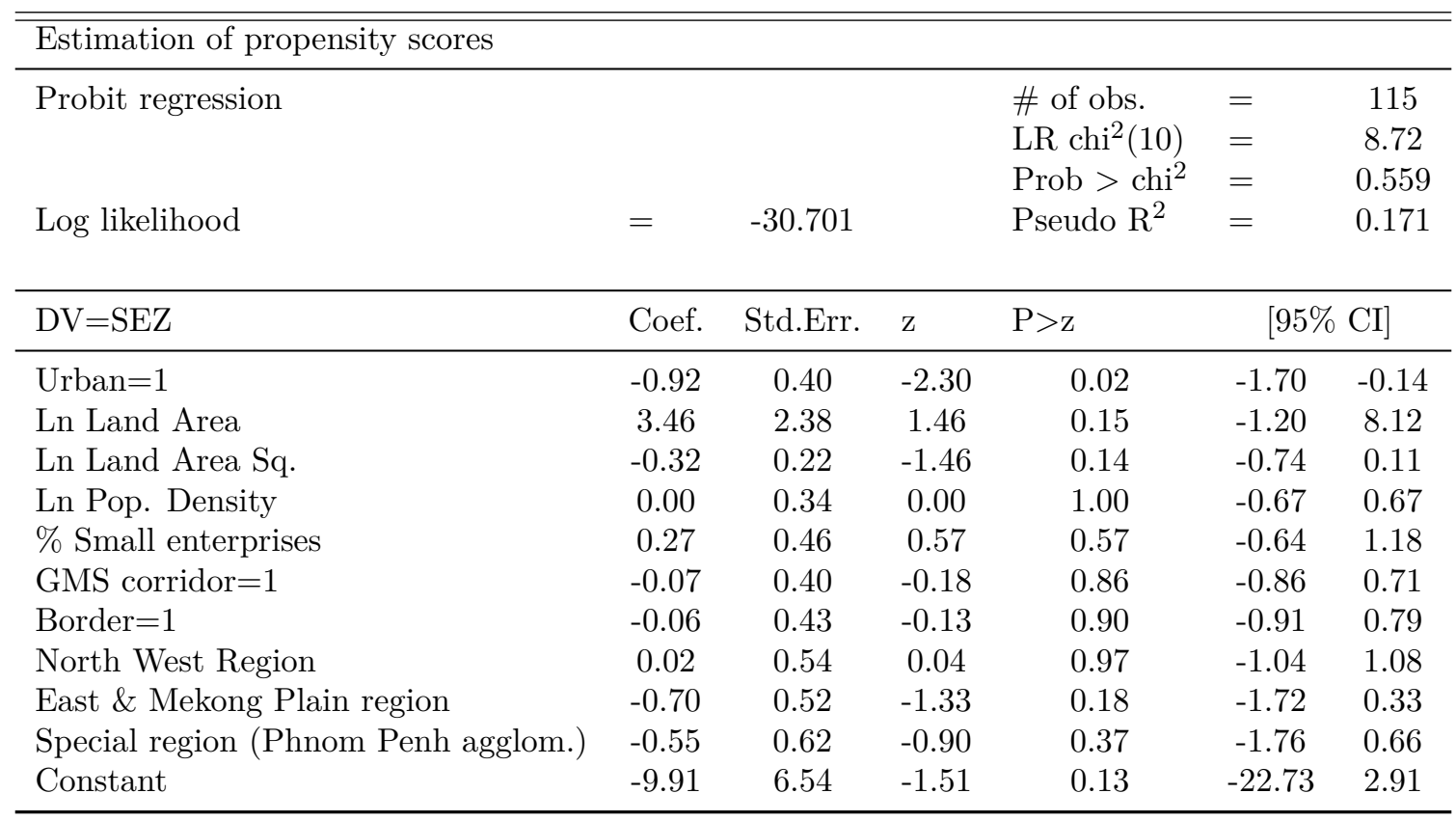


In terms of absolute and relative employment growth, Table 3 Panel $\mathrm{C}$ indicates that in aggregate and at a cursory glance, mean values for either the treatment or control clients appear at first to be fairly minimal - between -0.04 and 0.02 and -0.01 and 0.01 , respectively. This is actually consistent with stylized facts from the literature on enterprise growth, ${ }^{22}$ which finds that growth and growth rate distributions of enterprises among the general population tend to be heavy-tailed, particularly with respect to employment growth (Daunfeldt \& Elert, 2013). In other words, we can expect that the majority of enterprises in any population tend to exhibit zero or minimal employment growth, while a few will exhibit either particularly high growth or decline, which has been found in previous settings to lead to net job creation averaging close to zero (Coad \& Rao, 2008; Davidsson et al., 2010, Mead \& Liedholm, 1998). ${ }^{23}$

This suggests that the more interesting phenomena of enterprise growth take place in the tails of the distribution, and has led enterprise growth literature toward shifting attention to understanding patterns and determinants for these subsets of firms in recent years (Coad et al., 2014). To explore this further descriptively within our sample, we create dummy indicators for observations where client businesses experienced employment growth, no change, or decline between consecutive loan cycles and run separate summary statistics on the size of employment growth and decline among the respective subsamples. Indeed, if we disaggregate differences between the treatment and control group, we do observe that there appears to be overall more job churning among the treatment group businesses, at least with respect to having any amount of growth or decline. On the one hand, we can observe that the treatment group appears to have somewhat higher rates of businesses having any employment decline. On the other hand, we observe that, for the share of observations where businesses grew, the average size of the employment growth is notably larger for the treatment than control group businesses (2.24 as opposed to 2.02 in absolute terms and 0.78 as opposed to 0.68 in relative terms). Meanwhile, for the share of observations where businesses declined, there is insignificant difference in the magnitude of the employment decrease. This may already provide suggestion that SEZ implementation may have led to a shift toward larger (and arguably better quality) enterprises given new opportunities and a decline in less viable ones.

Table 3 also helps set initial ideas concerning the clients and businesses in our synthetic comparison groups. ${ }^{24}$ We observe that both the weighted treatment and control groups are fairly evenly split between male and female clients and that they are typically middle aged and in households with other dependents. On average, businesses had between 1.62 to 1.67 total employees (that is, including the owner) and USD 21,700-23,800 in total assets at the time of clients' first loan cycles. For both the treatment and control groups, the majority of businesses were in the agriculture or trade sectors. Furthermore, the typical loan size was around USD 5,000-5,700, with an annualized percentage rate of around 23-24 and loan duration of a little over one and a half years. It is worth noting that this is a larger loan size and duration than the average client in the nationally representative sample. This highlights that the treatment branches did have a different orientation toward small (as opposed to micro) enterprises.

\section{Empirical Analysis}

Our empirical strategy is to exploit the geographic and temporal variation in the implementation of Cambodian SEZs during our sample study period and combine inverse 
Table 3: Summary statistics on client and loan-level characteristics between treatment and synthetic control branch districts

This table presents summary statistics for client and loan-level characteristics between weighted treatment and synthetic control observations. Panel A variables are run at the unique client-level based on characteristics at the time of their first loan initiation in the dataset. Panel B variables are run at the loan-level across all loan initiations in the dataset. The full estimation sample includes clients from 115 branches covering the period from 2011 to 2016, from which there are 9 branches in SEZ locations and 106 branches in non-SEZ locations. We estimate propensity scores for both SEZ and non-SEZ branch districts on district-level contextual factors driving "treatment" - i.e. placement of SEZs. We then apply inverse probability of treatment weighting to create synthetic counterfactual groups for the DiD estimation.

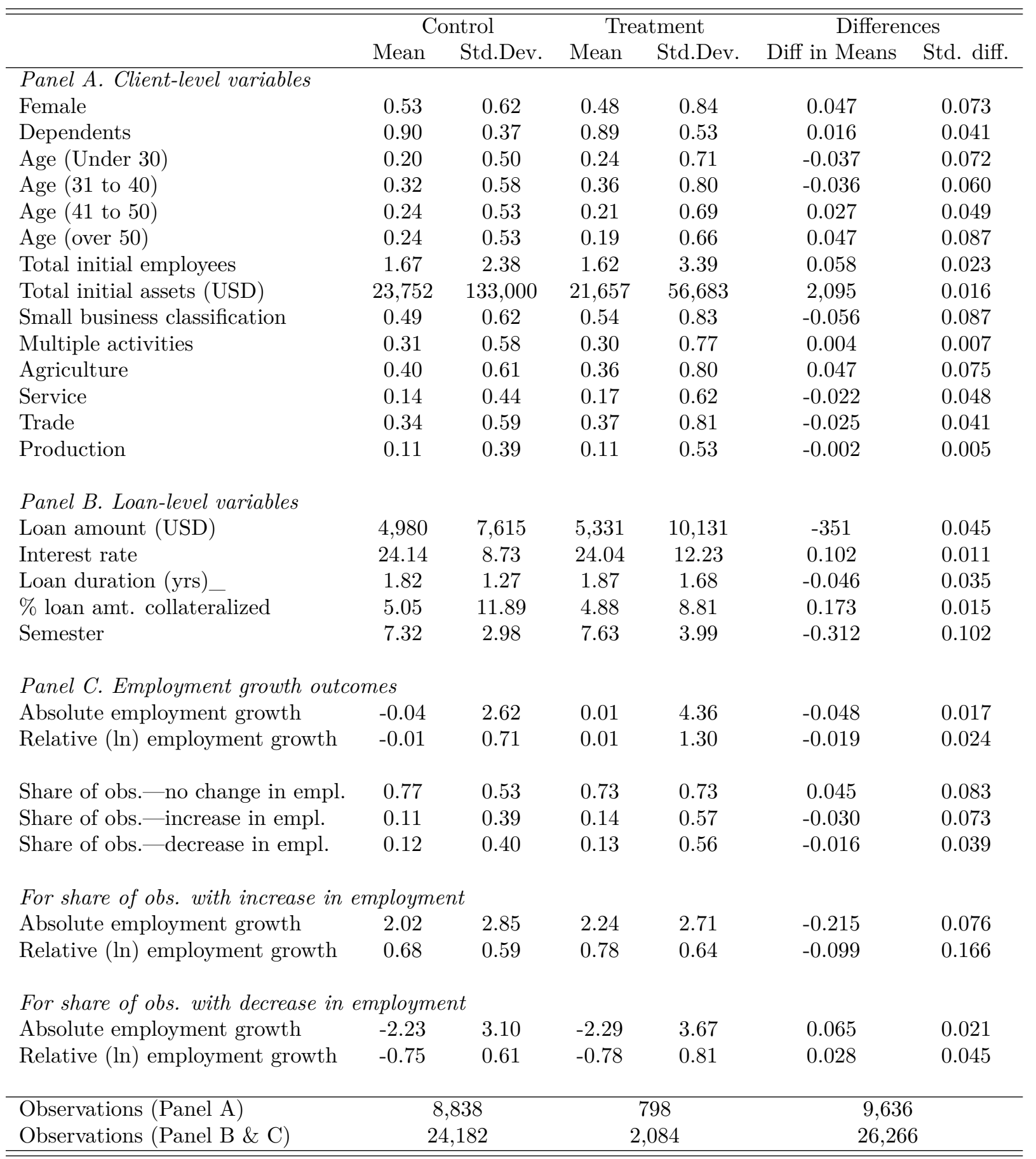


probability weighting with a difference-in-differences approach. In short, propensity score weighting should help mitigate selection into treatment based on observables, and the difference-in-differences should further mitigate selection on unobservables that are invariant by location (district) and time, conditional on other covariates from extant literature.

\subsection{Event study}

In section 4.3, we provided evidence supporting the argument that our treatment and synthetic control group are well balanced on observable district- and client-level factors. However, we acknowledge that one may be concerned there are other unobservable factors which differ between the treatment and control districts and which may drive differences in business growth outcomes. Thus, in the following section, we start off by using event study models to demonstrate that the patterns of business growth between the treatment and control branches did not significantly differ in the pre-treatment period and that the parallel trends assumption appears to hold.

As a first step, we investigate the key identifying assumption of difference-in-differences models - namely that growth outcomes for clients in the treatment and control districts would have followed similar trends in the absence of SEZ implementation. The validity of this identifying assumption is explored here using an event study model, which introduces lead and lagged treatment dummy indicators to test whether there are any signs of differential pre-trends. We construct the lead and lag time periods at the daily-level from the specific SEZ start date and in semesterly blocks. ${ }^{25}$ For example, loan applications between 183 to 1 days prior to the SEZ start date would be considered part of the 0 to 6 month lead period (and used as the reference period for comparison) and loan applications from the SEZ start date to 183 days after would be considered part of the 0 to 6 month lag period. More specifically, for individual $i$ in district $d$ and time $t$, we estimate an event study model using following form:

$$
y_{i d t}=\theta_{d}+\gamma_{t}+\sum_{j=m}^{k} \beta_{j}\left(D i D_{i d t} \times D_{t}^{j}\right)+\chi \text { Controls }_{i d t}+u_{i d t}
$$

Where the dependent variable $y$ is either: 1) absolute employee growth or 2) log (relative) employee growth. DiD is an indicator variable set to 1 if district $d$ had an SEZ implemented during a given study period $t$, otherwise $0 . D_{t}^{j}$ is an indicator variable set to 1 if time period $t$ is equal to $j$ (where $j$ can represent time periods from the minimum lead time period $m$ to the maximum lagged time period of $k$ ), and otherwise 0 . Put in other words, $\sum_{j=m}^{k} \beta_{j}\left(D i D_{i d t} \times D_{t}^{j}\right)$ denotes separate estimators for each time period before, during, and after SEZ implementation, whose parameters $\beta_{j}$ capture whether there are any differential growth outcomes in the given time period between clients in the treatment and control branches. Finally, $\theta$ and $\gamma$ indicate branch district and time fixed effects, respectively, and Controls denotes a vector of client- and business-level controls, which are described below.

Under the null hypothesis of no differential pre-treatment trends, we would expect the parameter $\beta$ on the lead treatment indicators to be zero (or statistically indistinguishable from zero) prior to the date of SEZ implementation. While not a main focus of this analysis, the coefficients on the lagged treatment indicators can also be interpreted as suggesting a slope-change in effects across time - capturing whether the treatment effect 
may perhaps grow stronger or diminish over time.

By design, the empirical strategy controls for factors that are time-invariant for branches across our study period (such as geographic location) and factors which affect all districts in given time periods (such as common macroeconomic shocks); that is, these factors are all purged from the estimates of $\beta$. As previously shown in section 4.3 , the treatment and control groups appear relatively balanced on most client, business, and district-level observables. Nevertheless, to control for possible differences in individuallevel characteristics between the clients in treatment and control branches, we introduce several relevant controls drawn from the extant literature (see discussion in Section 4.1).

Table 4 provides the results from the event study model for both absolute and log employment growth as main dependent variables. We observe that the difference in employment growth outcomes between the treatment and control groups were statistically indistinguishable from one another until the period of SEZ implementation for either indicator. Thereafter, we begin to observe indication that employment growth for treatment group clients between consecutive loan cycles began to significantly differ in the first 0 to 6 months after implementation, with the differential growing sequentially in magnitude 13-18 months and 19-24 months later. These results are mirrored in Figures 4 and 5 , which plot the estimates of the coefficients $\beta_{j}$ for the lead and lag dummies (with 95 percent confidence intervals). 
Table 4: Event study model estimating difference between treatment and control businesses' employment growth during pre and post-SEZ implementation periods

This table presents coefficient estimates for an event study model measuring differences in absolute and log employment growth between SEZ (treatment) and non-SEZ (control) district clients prior and post SEZ implementation. The zero to six month lead period serves as the comparison period. The full estimation sample includes clients from 115 branches covering the period from 2011 to 2016, from which there are 9 branches in SEZ locations and 106 branches in non-SEZ locations. We estimate propensity scores for both SEZ and non-SEZ branch districts on district-level contextual factors driving "treatment"-i.e. placement of SEZs. We then apply inverse probability of treatment weighting to create synthetic counterfactual groups for the DiD estimation. Client controls include gender, household type, and age. Business controls include whether a client's business is a micro- or small enterprise, in its first loan cycle or not, economic sector of activity, and whether the client engages in multiple economic activities. Standard errors are clustered at the branch and semester-level. $p$-values in parentheses ${ }^{* * *} \mathrm{p}<0.01,{ }^{* *} \mathrm{p}<0.05,{ }^{*} \mathrm{p}<0.1$.

\begin{tabular}{lccc}
\hline \hline & DV=Abs. empl. growth & DV=Ln empl. growth \\
\cline { 2 - 2 } SEZ district X 19-24 month lead & $(1)$ & $(2)$ \\
SEZ district X 13-18 month lead & $(0.189$ & 0.073 \\
& -0.364 & $(0.386)$ \\
SEZ district X 6-12 month lead & $(0.312)$ & -0.033 \\
& -0.069 & $(0.799)$ \\
SEZ district X 0-6 month lag & $(0.616)$ & 0.037 \\
& 0.340 & $(0.348)$ \\
SEZ district X 6-12 month lag & $(0.113)$ & $0.183^{* * *}$ \\
& 0.037 & $(0.003)$ \\
SEZ district X 13-18 month lag & $(0.871)$ & 0.086 \\
& $0.385^{* *}$ & $(0.391)$ \\
SEZ district X 19-24 month lag & $(0.049)$ & $0.222^{* * *}$ \\
& $1.078^{* *}$ & $(0.005)$ \\
Additional controls: & $(0.012)$ & $0.502^{* * *}$ \\
Branch fixed effects & & $(0.004)$ \\
Semester fixed effects & Yes & \\
Client controls & Yes & Yes \\
Business controls & Yes & Yes \\
Province X semester interaction & Yes & Yes \\
\hline Observations & No & Yes \\
$R^{2}$ & 6,901 & No \\
\hline \hline
\end{tabular}




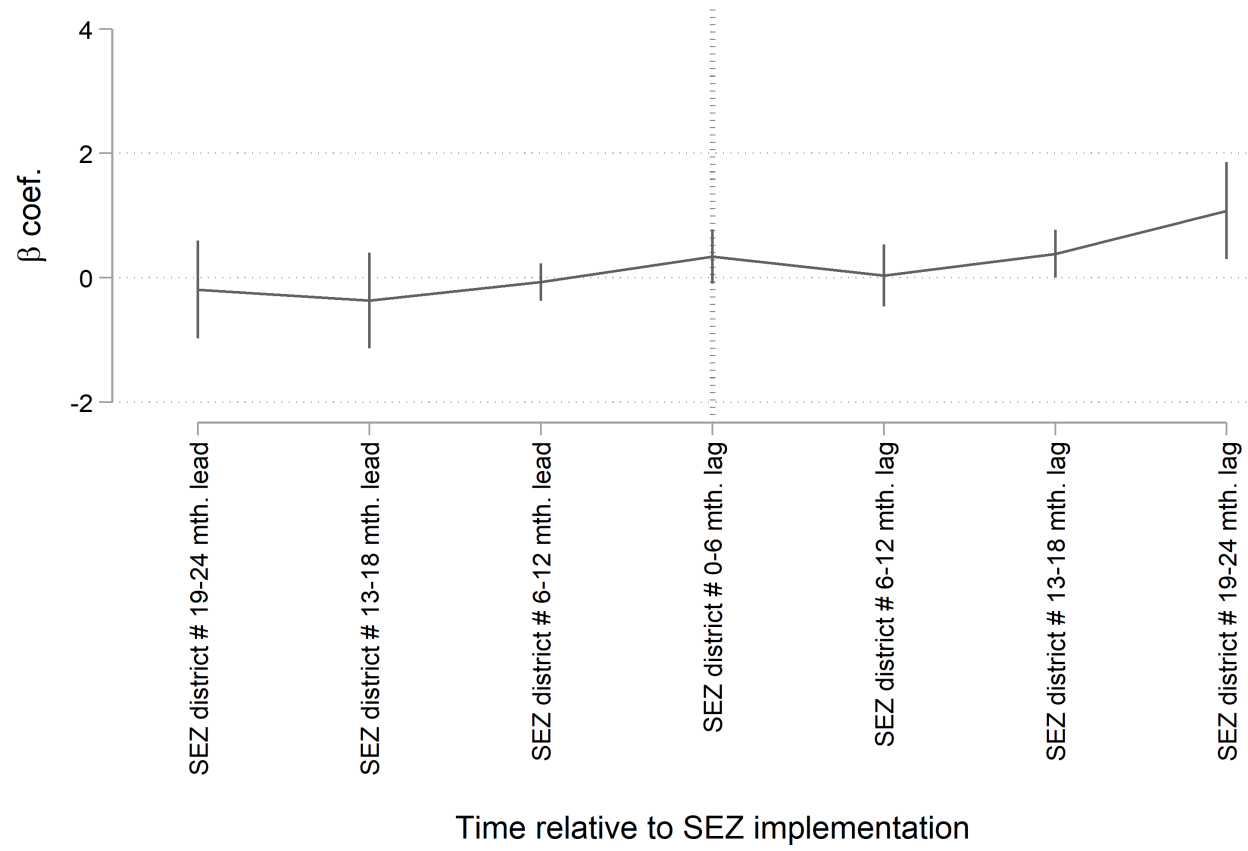

Figure 4: This figure depicts results from the event study model (detailed in Eq. 2 ) where absolute employment growth is the dependent variable and $\beta_{j}$ captures whether there are any statistically significant differences in growth outcomes between clients in the treatment and control branches in the periods leading up to SEZ implementation and the periods after implementation.

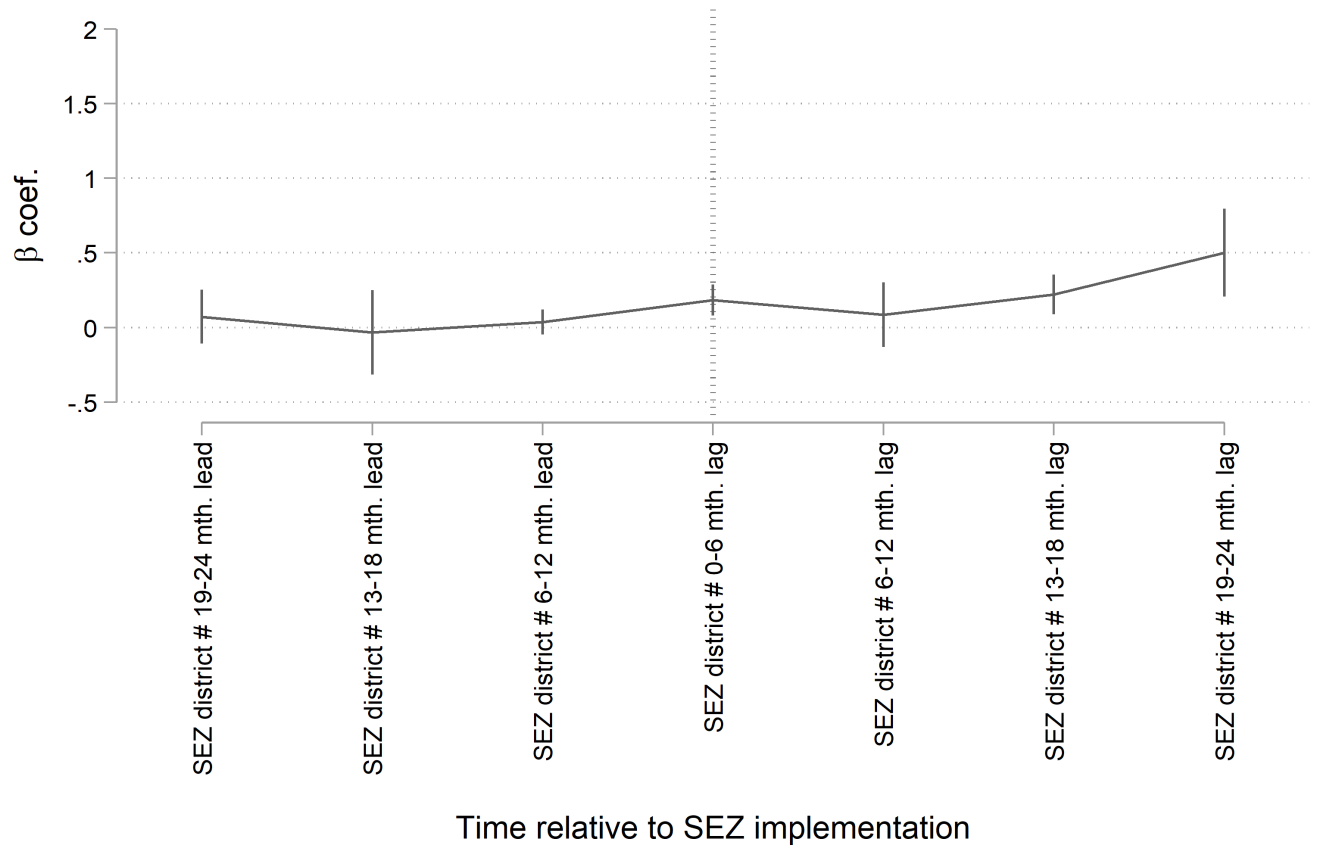

Figure 5: This figure depicts results from the event study model (detailed in Eq. 2 where relative (ln) employment growth is the dependent variable and $\beta_{j}$ captures whether there are any statistically significant differences in growth outcomes between clients in the treatment and control branches in the periods leading up to SEZ implementation and the periods after implementation. 


\subsection{Generalized Model}

Results from the event study are consistent with our first hypothesis that the implementation of SEZs has positive effect on employment growth of our research partner's entrepreneurial credit clients. To provide a concise means for the effect magnitude during our study sample and to subject the estimates to specification and robustness tests, we next move on to a generalized difference-in-differences model of the following form:

$$
y_{i d t}=\theta_{d}+\gamma_{t}+\beta D i D_{i d t}+\chi \text { Controls }_{i d t}+u_{i d t}
$$

Where, rather than using separate interactions for each period, the model has a single estimator, DiD, which denotes whether a district $d$ has had SEZ implementation in time $t$ (that is, an interaction on "treatment" and the post "treatment" period). The single parameter $\beta$ is our main coefficient of interest in this simple specification. All other variables are as previously described.

We use the generalized model to also test the robustness of our main results to the included controls. Thus, in Table 5, we summarize the results of different model specifications which include a (a) baseline model with just district and time (semester) fixed effects and our main difference-in-differences estimator, (b) including client-level controls and business-level controls, (c) further "controlling" for loan-level characteristics, and (d) also adding in province-semester interactions dummies. Model 2 is our preferred specification because it parallels the event-study models in Section 5.1). The inclusion of loan-level characteristics as explanatory variables in model 3 may understandably be an example of "bad controls" as they are particularly likely to be endogenous; their inclusion is more to demonstrate the general robustness of results. Model 4 controls for time variant factors across provinces that may differentially influence growth outcomes. In this regard, a relevant study by Malesky (2009) found that the quality of business environments in Cambodia for some provinces changed over time in the years prior to our study period. Thus, the province-semester interaction terms are used to purge province-specific time trends from our main estimate of interest and demonstrate that the main results still remain.

In columns 5 through 8 of Table 5, we observe that the implementation of SEZs increased employment growth in relative terms by roughly 15 to 26 percent between loan cycles for clients in SEZ districts with respect to clients in control districts. In absolute terms, the DiD estimators in columns 1 through 5 indicate between a 41 to 73 percent increase in employment growth in absolute terms between the treatment and control districts before and after the SEZ implementation. Taking into consideration the mean initial business size for clients from our sample of roughly 1.7 total employees (see Table 3), an alternative way of interpreting the economic magnitude of the effects on clients is that every 10 client businesses in the SEZ districts started out with approximately 17 employees combined and ended up with roughly 3 to 4 more additional employees combined compared to similar client businesses in the control districts, following SEZ implementation. It is worth reminding that this represents the average difference in employment growth between treatment and control clients typically around one year from a given loan cycle.

We can further observe that the additional array of controls improve the predictive power of our models (increasing the R-squared for relative growth by roughly 20 percent, excluding the province-year interactions) but that our main results are quite robust to their inclusion. For example, our DiD estimator remains significant at the 5 percent 
level in all specifications and the coefficient marginally changes even with the inclusion of client controls and business-level controls (columns 2 and 6), and loan characteristics (columns 3 and 7). The inclusion of province-year interactions (columns 4 and 8) does lead to more noticeable changes to the economic size of results. However, it is worth noting that their inclusion increases both the statistical and economic size of results rather than attenuates them. Moreover, the results would generally support the underlying argument that differences in subnational environments ultimately play a primary role in influencing clients' business growth outcomes.

We also run a number of sensitivity tests to demonstrate that the main results are fairly insensitive to changes in various aspects of the analysis' construction, including using alternative methods for using the propensity scores to construct a synthetic control group and including or excluding specific branches from the treatment group. Furthermore, we present suggestive evidence that the main result is unlikely to be driven by differences in client attrition rates between treatment and control districts. One factor which does appear to have important influence on results (both in this study and in empirical enterprise growth studies more generally) are the inclusion or exclusion of extreme outliers. However, it is worth noting that our main results still go through even after winsorizing the top and bottom 5 percentiles of observations. ${ }^{26}$ 
Table 5: The impact of SEZ implementation on employment growth in clients' businesses

This table presents coefficient estimates for a generalized difference-in-differences model measuring the effect of SEZ implementation on absolute and relative (log) annualized employment growth. DiD estimator denotes whether a district $d$ had SEZ implementation in time $t$ (i.e. an interaction on being in the "treatment" group and in the post "treatment" period). The estimation sample includes clients from 115 branches covering the period from 2011 to 2016 , from which there are 9 branches falling in the treatment group and 106 falling in the control. We estimate propensity scores for both treatment and control branch districts on district-level factors driving placement of SEZs. We then apply inverse probability of treatment weighting to create synthetic counterfactual groups for the DiD estimation. We estimate different model specifications which include a (a) baseline model with just district and time (semester) fixed effects and our main difference-in-differences estimator, (b) including client-level controls and business-level controls, (c) further "controlling" for loan-level characteristics, and (d) also adding in province-semester interactions dummies. Client controls include gender, household type, and age. Business controls include whether a client's business is a micro- or small enterprise, in its first loan cycle or not, economic sector of activity, and whether the client engages in multiple economic activities. Loan characteristics include ln. loan amount (USD), interest rate, loan duration, and percent of loan amount collateralized. Standard errors are clustered at the branch and semester-level. $p$-values in parentheses $* * * \mathrm{p}<0.01,{ }^{* *} \mathrm{p}<0.05,{ }^{*} \mathrm{p}<0.1$.

\begin{tabular}{|c|c|c|c|c|c|c|c|c|}
\hline & \multicolumn{4}{|c|}{ DV=Abs. employment growth } & \multicolumn{4}{|c|}{ DV=Rel. (Ln) employment growth } \\
\hline & $(1)$ & $(2)$ & (3) & (4) & (5) & (6) & $(7)$ & $(8)$ \\
\hline DiD estimator & $\begin{array}{c}0.425^{* * *} \\
(0.000)\end{array}$ & $\begin{array}{c}0.414^{* * *} \\
(0.004)\end{array}$ & $\begin{array}{c}0.410^{* * *} \\
(0.008)\end{array}$ & $\begin{array}{l}0.732^{* *} \\
(0.046)\end{array}$ & $\begin{array}{c}0.157^{* * *} \\
(0.000)\end{array}$ & $\begin{array}{c}0.156^{* * *} \\
(0.001)\end{array}$ & $\begin{array}{c}0.150^{* * *} \\
(0.003)\end{array}$ & $\begin{array}{l}0.255^{* *} \\
(0.023)\end{array}$ \\
\hline Additional controls: & & & & & & & & \\
\hline Branch fixed effects & Yes & Yes & Yes & Yes & Yes & Yes & Yes & Yes \\
\hline Semester fixed effects & Yes & Yes & Yes & Yes & Yes & Yes & Yes & Yes \\
\hline Client controls & No & Yes & Yes & Yes & No & Yes & Yes & Yes \\
\hline Business controls & No & Yes & Yes & Yes & No & Yes & Yes & Yes \\
\hline Loan characteristics & No & No & Yes & No & No & No & Yes & No \\
\hline Province X semester interaction & No & No & No & Yes & No & No & No & Yes \\
\hline Observations & 6,901 & 6,901 & 6,901 & 6,887 & 6,901 & 6,901 & 6,901 & 6,887 \\
\hline$R^{2}$ & 0.039 & 0.045 & 0.046 & 0.087 & 0.060 & 0.066 & 0.070 & 0.127 \\
\hline
\end{tabular}




\subsection{Exploration on mechanisms and differential outcomes}

Finally, we investigate client- and district-level factors that may lead to differential effects on business growth when access to finance is combined with SEZ implementation. This allows us to test our additional hypotheses relevant to microcredit, enterprise growth, and SEZ literature, as well as provide insights into some of the possible transmission mechanisms. To do so within the framework of our previous analysis, we introduce these factors as interaction terms with our main difference-in-differences estimator and rerun our generalized model (section 5.2, equation 3). The coefficients of interest for these models are on the additional interaction term, where a significant positive or negative coefficient can be interpreted as the factor moderating the intensity of the treatment effect.

\subsubsection{What individual-level characteristics drive differential outcomes?}

We begin by exploring the paper's hypotheses $2 \mathrm{a}$ to $\mathrm{cd}$ on client- and business-level factors. This is to test the intuition that a certain share of the targeted entrepreneurial population can benefit quite a lot from microcredit, given tailored and context-specific approaches that takes into account other constraints. First, we test whether there were signs of differential effects observed between small versus micro enterprise clients from SEZ implementation (Hypothesis 2a). This is in line with Beck (2015)'s suggestion that moving up the firm ladder to focus on small rather than micro enterprises might have more potential to be transformative and create jobs. It is also pertinent to check if this finding (or a lack thereof) is consistent across both relative and absolute growth measures since the enterprise growth literature has established that absolute growth indicators tend to be biased to highlighting growth in already larger businesses (see Daunfeldt et al. (2014)).

Table 6 reports both main SEZ effects and the differential effects when interacted with our client-level factors of interest. In columns 1 and 7 , we observe positive and highly significant coefficients for the interaction between small businesses and the DiD estimator of large economic sizes, whether in absolute or relative terms. This finding is a bit more striking when noting that we do not observe significant relationship with employment growth for small business clients outside of SEZ areas - rather, some signs of slightly negative relationships. ${ }^{27}$ It is also important to note that coefficients for the DiD main effects in columns 1 and 7 remain both statistically and economically significant. This implies that the impact of the SEZ implementation on business growth wasn't solely limited to already larger enterprises and that microenterprise clients benefited as well.

Next, we explore whether there were differential effects from SEZ implementation for clients whose businesses were in different sectors of economic activity (Hypothesis 2b). As described in section 2.2, theoretical literature on SEZs posits both "linkage effects", where SEZ firms come to source inputs from domestic producers of primary materials and industrial goods, and "indirect spillover effects", where zones come to rely on their surrounding area for satisfaction of basic needs for accommodation, consumer services, and other place-specific non-zone activities. Given this theoretical framework, we roughly equate and interpret effects on production and trade sector businesses as likely to be more closely linked to the former, and effects on service businesses with the latter.

Taking the results depicted in Table 6 columns 2-5 and 8-11 as a whole, our analysis doesn't find particularly strong evidence that "linkage effects" outweighed "indirect spillover effects". For example, there are some signs of positive interactions for service sector clients in absolute terms and and trade sector clients in relative terms in columns 2 
and 6, respectively. However, these relationships do not appear to be highly significant or consistent across indicators. As such, we interpret the overall results as suggesting both effects occurred to some extent within our study context.

Finally, we also explore differential effects for intensive versus extensive margin clients (Hypothesis 2c), which is captured by our dummy indicator for a given client's first loan cycle. This helps us test whether our main results appear to be driven more by the provider's pre-existing clients or first-time clients who may have experienced increased propensity to access formal credit in order to take advantage of better growth opportunities. At a cursory level, we posit this may serve as a rough proxy for capturing the life cycle stage of a client's business - that is, more mature versus younger businesses.

In Table 6, columns 6 and 10, we again observe mixed and largely insignificant interactions between the DiD estimator and a client's first loan cycle, indicating that employment growth driven by SEZ implementation was not necessarily more pronounced for extensive rather than intensive margin clients. This appears to somewhat contrast with findings by Banerjee, Duflo, et al. (2015), who observe the largest positive differential effects in terms of business growth from increased access to credit concentrated amongst clients with longer-standing intensive margin businesses. In our case, however, we also acknowledge that the "first loan cycle" dummy may not necessarily be able to distinguish between younger versus more mature businesses, nor does it account for whether the client has formal credit from other providers. 
Table 6: Extended analyses on borrower-level factors affecting intensity of treatment effects

The table presents coefficient estimates for a generalized difference-in-differences model measuring the effect of SEZ implementation on client business growth. DiD estimator denotes whether a district $d$ had SEZ implementation in time $t$ (i.e. an interaction on being in the "treatment" group and in the post "treatment" period). We explore differential treatment effects driven by client-level factors through the inclusion of an additional interaction term. All models also include the previously established controls, including client demographics, business characteristics, branch fixed effects, and time fixed effects. Standard errors are clustered at the branch and semester-level. $p$-values in parentheses ${ }^{* * *} \mathrm{p}<0.01,{ }^{* *} \mathrm{p}<0.05,{ }^{*} \mathrm{p}<0.1$.

\begin{tabular}{|c|c|c|c|c|c|c|c|c|c|c|c|c|}
\hline & \multicolumn{6}{|c|}{ DV $=$ Abs. employment growth } & \multicolumn{6}{|c|}{ DV $=$ Rel. (Ln) employment growth } \\
\hline & (1) & (2) & (3) & (4) & (5) & (6) & (7) & (8) & (9) & (10) & (11) & (12) \\
\hline Main effects & & & & & & & & & & & & \\
\hline DiD estimator & $\begin{array}{c}0.25^{* * *} \\
(0.00)\end{array}$ & $\begin{array}{c}0.43^{* * *} \\
(0.00)\end{array}$ & $\begin{array}{c}0.37^{* * *} \\
(0.00)\end{array}$ & $\begin{array}{c}0.38^{* * *} \\
(0.00)\end{array}$ & $\begin{array}{c}0.47^{* * *} \\
(0.00)\end{array}$ & $\begin{array}{c}0.47^{* * *} \\
(0.00)\end{array}$ & $\begin{array}{c}0.12^{* * *} \\
(0.00)\end{array}$ & $\begin{array}{c}0.16^{* * *} \\
(0.00)\end{array}$ & $\begin{array}{c}0.16^{* * *} \\
(0.00)\end{array}$ & $\begin{array}{c}0.13^{* * *} \\
(0.00)\end{array}$ & $\begin{array}{c}0.17^{* * *} \\
(0.00)\end{array}$ & $\begin{array}{c}0.14^{* * *} \\
(0.00)\end{array}$ \\
\hline Small business & $\begin{array}{l}-0.06 \\
(0.30)\end{array}$ & $\begin{array}{l}-0.05 \\
(0.35)\end{array}$ & $\begin{array}{c}-0.05 \\
(0.36)\end{array}$ & $\begin{array}{l}-0.05 \\
(0.36)\end{array}$ & $\begin{array}{l}-0.05 \\
(0.37)\end{array}$ & $\begin{array}{l}-0.05 \\
(0.35)\end{array}$ & $\begin{array}{l}-0.02 \\
(0.25)\end{array}$ & $\begin{array}{c}-0.02 \\
(0.28)\end{array}$ & $\begin{array}{l}-0.02 \\
(0.28)\end{array}$ & $\begin{array}{c}-0.02 \\
(0.29)\end{array}$ & $\begin{array}{l}-0.02 \\
(0.28)\end{array}$ & $\begin{array}{l}-0.02 \\
(0.28)\end{array}$ \\
\hline Agriculture & $\begin{array}{c}0.05 \\
(0.87)\end{array}$ & $\begin{array}{c}0.05 \\
(0.88)\end{array}$ & $\begin{array}{c}0.05 \\
(0.89)\end{array}$ & $\begin{array}{c}0.05 \\
(0.88)\end{array}$ & $\begin{array}{c}0.05 \\
(0.89)\end{array}$ & $\begin{array}{c}0.04 \\
(0.89)\end{array}$ & $\begin{array}{c}-0.00 \\
(0.98)\end{array}$ & $\begin{array}{l}-0.00 \\
(0.98)\end{array}$ & $\begin{array}{l}-0.00 \\
(0.97)\end{array}$ & $\begin{array}{l}-0.00 \\
(0.99)\end{array}$ & $\begin{array}{l}-0.00 \\
(0.97)\end{array}$ & $\begin{array}{l}-0.00 \\
(0.98)\end{array}$ \\
\hline Service & $\begin{array}{c}0.08 \\
(0.81)\end{array}$ & $\begin{array}{c}0.08 \\
(0.82)\end{array}$ & $\begin{array}{c}0.06 \\
(0.85)\end{array}$ & $\begin{array}{c}0.08 \\
(0.81)\end{array}$ & $\begin{array}{c}0.07 \\
(0.83)\end{array}$ & $\begin{array}{c}0.07 \\
(0.82)\end{array}$ & $\begin{array}{c}-0.00 \\
(0.98)\end{array}$ & $\begin{array}{c}-0.00 \\
(0.98)\end{array}$ & $\begin{array}{c}-0.00 \\
(0.99)\end{array}$ & $\begin{array}{c}-0.00 \\
(0.99)\end{array}$ & $\begin{array}{c}-0.00 \\
(0.97)\end{array}$ & $\begin{array}{c}-0.00 \\
(0.98)\end{array}$ \\
\hline Trade & $\begin{array}{c}0.09 \\
(0.79)\end{array}$ & $\begin{array}{c}0.09 \\
(0.79)\end{array}$ & $\begin{array}{c}0.09 \\
(0.79)\end{array}$ & $\begin{array}{c}0.09 \\
(0.79)\end{array}$ & $\begin{array}{c}0.08 \\
(0.80)\end{array}$ & $\begin{array}{c}0.08 \\
(0.79)\end{array}$ & $\begin{array}{l}-0.00 \\
(1.00)\end{array}$ & $\begin{array}{l}-0.00 \\
(1.00)\end{array}$ & $\begin{array}{l}-0.00 \\
(1.00)\end{array}$ & $\begin{array}{l}-0.00 \\
(0.99)\end{array}$ & $\begin{array}{l}-0.00 \\
(0.99)\end{array}$ & $\begin{array}{c}0.00 \\
(1.00)\end{array}$ \\
\hline Production & $\begin{array}{c}0.17 \\
(0.66)\end{array}$ & $\begin{array}{c}0.17 \\
(0.66)\end{array}$ & $\begin{array}{c}0.17 \\
(0.66)\end{array}$ & $\begin{array}{c}0.17 \\
(0.66)\end{array}$ & $\begin{array}{c}0.19 \\
(0.64)\end{array}$ & $\begin{array}{c}0.17 \\
(0.67)\end{array}$ & $\begin{array}{c}0.03 \\
(0.83)\end{array}$ & $\begin{array}{c}0.03 \\
(0.84)\end{array}$ & $\begin{array}{c}0.03 \\
(0.84)\end{array}$ & $\begin{array}{c}0.03 \\
(0.82)\end{array}$ & $\begin{array}{c}0.03 \\
(0.82)\end{array}$ & $\begin{array}{c}0.03 \\
(0.83)\end{array}$ \\
\hline First loan cycle & $\begin{array}{l}0.08^{*} \\
(0.09)\end{array}$ & $\begin{array}{l}0.08^{*} \\
(0.09)\end{array}$ & $\begin{array}{l}0.08^{*} \\
(0.09)\end{array}$ & $\begin{array}{l}0.08^{*} \\
(0.10)\end{array}$ & $\begin{array}{l}0.08^{*} \\
(0.10)\end{array}$ & $\begin{array}{l}0.09^{*} \\
(0.07)\end{array}$ & $\begin{array}{c}0.01 \\
(0.44)\end{array}$ & $\begin{array}{c}0.01 \\
(0.44)\end{array}$ & $\begin{array}{c}0.01 \\
(0.45)\end{array}$ & $\begin{array}{c}0.01 \\
(0.44)\end{array}$ & $\begin{array}{c}0.01 \\
(0.45)\end{array}$ & $\begin{array}{c}0.01 \\
(0.57)\end{array}$ \\
\hline Client-level interaction effects & & & & & & & & & & & & \\
\hline Small business $\mathrm{X} D i D$ estimator & $\begin{array}{c}0.23^{* * *} \\
(0.00)\end{array}$ & & & & & & $\begin{array}{c}0.06^{* * *} \\
(0.01)\end{array}$ & & & & & \\
\hline Agriculture $\mathrm{X} D i D$ estimator & & $\begin{array}{l}-0.06 \\
(0.48)\end{array}$ & & & & & & $\begin{array}{l}-0.01 \\
(0.63)\end{array}$ & & & & \\
\hline Service X $D i D$ estimator & & & $\begin{array}{l}0.25^{*} \\
(0.09)\end{array}$ & & & & & & $\begin{array}{l}-0.03 \\
(0.65)\end{array}$ & & & \\
\hline Trade X DiD estimator & & & & $\begin{array}{c}0.07 \\
(0.38)\end{array}$ & & & & & & $\begin{array}{c}0.06 \\
(0.19)\end{array}$ & & \\
\hline Production X $D i D$ estimator & & & & & $\begin{array}{c}-0.29 \\
(0.12)\end{array}$ & & & & & & $\begin{array}{c}-0.06 \\
(0.42)\end{array}$ & \\
\hline First loan cycle X $D i D$ estimator & & & & & & $\begin{array}{l}-0.11 \\
(0.38)\end{array}$ & & & & & & $\begin{array}{c}0.03 \\
(0.71)\end{array}$ \\
\hline Observations & 6,901 & 6,901 & 6,901 & 6,901 & 6,901 & 6,901 & 6,901 & 6,901 & 6,901 & 6,901 & 6,901 & 6,901 \\
\hline$R^{2}$ & 0.045 & 0.045 & 0.045 & 0.045 & 0.045 & 0.045 & 0.066 & 0.066 & 0.066 & 0.067 & 0.066 & 0.066 \\
\hline
\end{tabular}




\subsubsection{What district- and SEZ-level contextual characteristics drive differential out- comes?}

We similarly explore the paper's hypotheses 3a to 3d on territorial-level determinants driving differential dynamic effects from SEZs. In line with Frick et al. (2018) and based on availability of relevant data, we introduce a number of district- and SEZ-level interaction terms with the DiD estimator to test whether and to what extent the various factors are shown to significantly moderate the intensity of SEZ-induced employment growth in the context of Cambodian microcredit clientele.

First, in relation to district characteristics, we construct dummy indicators for clients in urban (vis-à-vis rural) districts and in country border (vis-à-vis interior) districts as proxies for size of and ease of access to markets. In Table 7 columns 1 and 5, we observe a significant positive relationship between the intensity of the treatment effect on employment growth for clients in areas with higher relative population density. Similarly, Columns 2 and 6 suggest that the effect on employment growth of SEZ implementation was also notably higher in country border districts compared with interior districts. This corresponds with the findings of Frick et al. (2018) and the general intuition that the size of local economic markets, ease of access to business inputs, or connection to other markets matter for providing growth opportunities for local businesses, particularly when combined with SEZs.

Second, in relation to SEZ characteristics, we test for interaction effects for SEZs that had earlier versus later start dates in our study period (as a proxy for zone maturity) and those in closer physical proximity to the service provider branch. For simplicity, these factors are captured as dummy variable set to 1 for locations whose SEZ started in the first half of the study period and whose distance between SEZ and branch locations are in the bottom 50th percentile, respectively. In column 7 of Table 7 , we observe that the client businesses in SEZs with longer maturity exhibit higher average relative employment growth and that the differential is economically large. This is in line with case studies documented by Farole (2011), which note that many successful SEZs have required sometimes lengthy incubation periods, with impacts becoming more pronounced years after implementation. Finally, in columns 4 and 8 , we observe somewhat mixed results for the interaction between close proximity branches and SEZs. However, it is worth clarifying that the constructed variable only captures the distance between the branch and SEZ locations rather than between a client's actual business location and SEZs specifically. As such, it may be a rather imprecise measure. 
Table 7: Extended analyses on district and SEZ-level factors affecting intensity of treatment effects

The table presents coefficient estimates for a generalized difference-in-differences model measuring the effect of SEZ implementation on client business growth. DiD estimator denotes whether a district $d$ had SEZ implementation in time $t$ (i.e., an interaction on being in the "treatment" group and in the post "treatment" period). We explore differential treatment effects driven by district and SEZ-level factors through the inclusion of an additional interaction term. The estimation sample includes clients from 115 branches covering the period from 2011 to 2016, from which there are 9 branches falling in the treatment group and 106 falling in the control. We estimate propensity scores for both treatment and control branch districts on district-level contextual factors driving placement of SEZs. We then apply inverse probability of treatment weighting to create synthetic counterfactual groups for the DiD estimation. All models also include the previously established controls, including client demographics, business characteristics, branch fixed effects, and time fixed effects. Standard errors clustered at the branch and year-level. $p$-values in parentheses $* * * \mathrm{p}<0.01,{ }^{* *} \mathrm{p}<0.05,{ }^{*} \mathrm{p}<0.1$.

\begin{tabular}{|c|c|c|c|c|c|c|c|c|}
\hline & \multicolumn{4}{|c|}{ DV=Abs. employment growth } & \multicolumn{4}{|c|}{ DV=Rel. (Ln) employment growth } \\
\hline & $(1)$ & $(2)$ & $(3)$ & $(4)$ & $(5)$ & $(6)$ & (7) & $(8)$ \\
\hline DiD estimator & $\begin{array}{c}0.31^{* * *} \\
(0.00)\end{array}$ & $\begin{array}{c}0.34^{* * *} \\
(0.00)\end{array}$ & $\begin{array}{c}0.37^{* * *} \\
(0.00)\end{array}$ & $\begin{array}{c}0.63 \\
(0.39)\end{array}$ & $\begin{array}{c}0.11^{\text {*** }} \\
(0.00)\end{array}$ & $\begin{array}{c}0.12^{* * *} \\
(0.00)\end{array}$ & $\begin{array}{c}0.12^{* * *} \\
(0.00)\end{array}$ & $\begin{array}{c}0.10 \\
(0.60)\end{array}$ \\
\hline
\end{tabular}

District-level interaction effects

Urban X DiD estimator

Country border X DiD estimator
$0.16^{* *}$
$(0.04)$
$0.11^{*}$
$0.07^{* * *}$
$(0.00)$

(0.07)

$0.05^{* * *}$

$(0.01)$

SEZ-specific interaction effects

SEZ start-1st half study period X DiD estimator

Close distance btw. SEZ and branch X DiD estimator
Observations

$R^{2}$
0.07

(0.42)

$\begin{array}{ccc} & & 0.07 \\ & & (0.42) \\ & & \\ & & \\ & & \\ & 6,901 & 6,901 \\ 0.045 & 0.045 & 0.045\end{array}$

\begin{tabular}{ccccc} 
& & & $0.05^{* *}$ & \\
& & & $(0.01)$ & \\
-0.23 & & & & 0.06 \\
$(0.75)$ & & & & $(0.74)$ \\
\hline 6,901 & 6,901 & 6,901 & 6,901 & 6,901 \\
0.045 & 0.067 & 0.067 & 0.067 & 0.067 \\
\hline
\end{tabular}




\section{Discussion}

To demonstrate the broader relevance of our results and argument, we pool data from a number of widely-publicized microcredit impact evaluations and use our analysis as a guiding framework to shed new light on their results.

While past microcredit RCT studies often document considerable heterogeneity in clients' business outcomes, none of the authors explicitly test how contextual features of the clients' business environments may help explain them. ${ }^{28}$ Meanwhile, scholars such as Pritchett \& Sandefur (2015) have highlighted that the key studies actually exhibit notable intra or inter-study heterogeneity in outcomes, as well contextual settings. Most recently, Meager (2019) pools data from past microcredit RCTs in a Bayesian meta study setting to explore whether heterogeneity in treatment effects across studies may be predicted or explained by variables defined at the "site"-level. However, her analysis mainly focuses on showing how differences in experimental protocol and in credit product design at the study-level explain outcomes, rather than exploring the role of country subregional business environment factors. By contrast, we argue that explicitly studying the links between business environments as covariates or moderators and client outcomes is a critical research gap to fill, given the importance of entrepreneurial transformation in microfinance's traditional theory of change.

We use the underlying theoretical channels and results from our analysis to guide this discussion. To recap, the main effect in our paper is driven by SEZ implementation, which is expected to improve local business environments by influencing investment (and hence general levels of wealth in the local economy), quality of local administration and institutions, access to infrastructure, and general business sentiment. While our data do not allow us to disentangle these individual mechanisms in the paper's main analysis, data from the prior RCTs collectively capture many relevant variables that we can use to do so. There are also "fixed' territorial factors that may make a local business environment more or less conducive to business growth, such as whether clients are located in higher population density areas or situated along country borders.

Figure 6 provides an overview of our main regression results and highlights the general importance of these various factors. It plots the coefficients and 95 percent confidence intervals from hypothesis tests on our main effect and on interactions testing for differential treatment effects from client-level and territorial-level factors. The visualization helps to reiterate that the overall main effect is economically large - for example, with SEZ implementation leading to 11 to 18 percent greater relative employment growth, and remains consistent regardless of the interacted client or business environment moderators. That having been said, we can also observe statistically and economically meaningful interactions for a variety of additional contextual factors. Furthermore, among them, the business environment-level factors seem to be particularly predictive vis-à-vis the client-level factors.

While our primary data do not allow us readily disentangle the underlying theoretical SEZ channels, data from the prior RCTs collectively capture many relevant variables that we can use to better explore them. To this end, we pool and analyze data from six widely-cited impact evaluations on microcredit. Combining these data allow us to increase statistical power and draw on greater variation in terms of business outcome indicators and business environment contexts being studied. ${ }^{29}$ We make the business outcome indicators across the studies comparable by standardizing their time units, adjusting any monetary indicators to PPP-adjusted USD, and applying log transformation (to reduce 


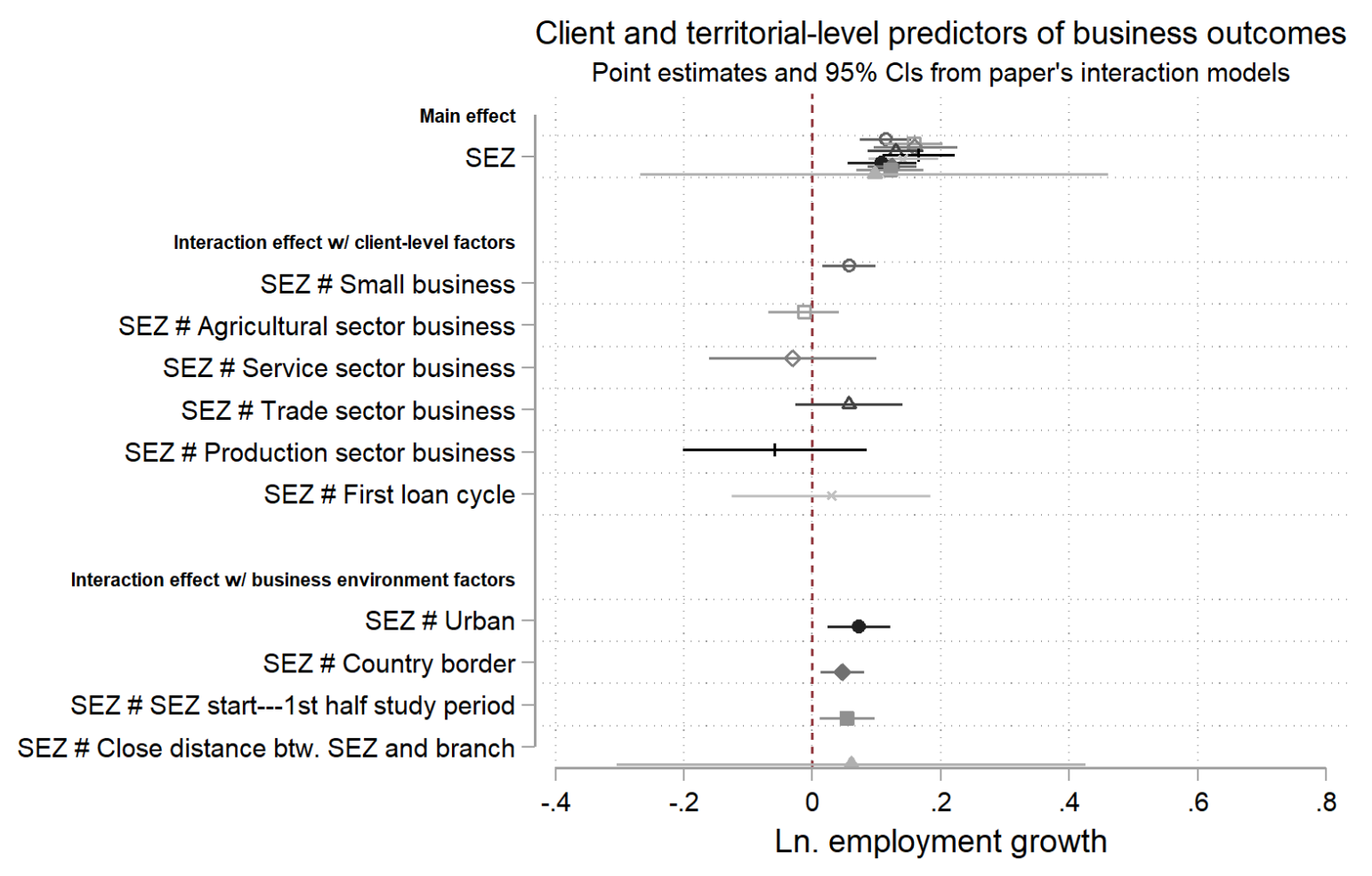

Figure 6: This figure summarizes results from the paper's exploration of contextual factors moderating treatment effect intensity. It provides point estimates and 95 percent confidence intervals for the main effect (DiD indicator for SEZ implementation) and interaction effect from client and territorial factors. These correspond to the interaction models described in Section 5.3 The models thus also include the full set of baseline controls and main term. The outcome of interest in the model results here are relative (ln.) employment growth.

the weight of outliers). ${ }^{30}$ We then identify or construct indicators on business environment factors related to the expected causal mechanisms underlying our hypotheses. With respect to our main effect channel, we identify or construct district-level proxies for: 1) levels of investment and wealth (income, availability of formal credit, and education), 2) quality of local institutions and rule of law (trust in formal institutions, trust in informal institutions, levels of crime), 3) access to better infrastructure (road, electricity, and water infrastructure access), and 4) general business environment indicators (favorable business sentiment, levels of competition, and female empowerment in an area). ${ }^{31}$ With respect to our moderating factors, we also identify variables capturing "fixed" territorial factors, including 5) whether a location is a country border area and the 6) population density in the study area. ${ }^{32}$ Variables related to the SEZ-specific factors we explore in our paper are understandably not captured nor relevant for prior RCTs.

For each contextual factor, we run pooled two sample t-tests to formally test a null hypothesis that it factor has no significant relationship with a given business indicator. We limit the analysis to "treatment" individuals from the studies, since this would be more in line with the clients from our study sample. While the main business metric in our paper is number of employees, we are able to draw on the wider array of business indicators available from the prior studies to also analyze expenses, revenues, and profits - and explore if the factors are associated with more dynamic businesses more generally. Note that the availability of specific contextual and business outcome variables does vary by 
study. Thus, the tests are run on subsets of the data (see Appendix Table D.1 for further details).

Key results are visually depicted in Figures 7 and 8 below. Similar to Figure6, we plot the coefficients and 95 percent confidence intervals from t-tests estimating the difference in clients' business employment and profits across the respective contextual business environment factors. ${ }^{33}$ Taken as a whole, we again find strong evidence that these factors play a critical role in influencing clients' business outcomes across a variety of metrics. We again see suggestive evidence that "fixed" aspects of business environments which capture aspects of market size and access, such as being located in areas with higher population density and along country borders, are positively related to clients' business employment and profits. More importantly, many of the business environment factors that can be shaped by national and subnational governments also play important and economically meaningful roles. In terms of socioeconomic standards, we find strong evidence that higher overall income levels, education and amount of capital in local markets are highly positively related to either employment and income. The quality of local institutions and rule of law also intuitively matters to a large degree. For example, we observe that high trust in formal institutions is particularly strongly related to greater employment and size for clients' businesses. This would be in line with intuition that entrepreneurs are more willing to risk visibility and grow their businesses when they are less concerned about bureaucratic inefficiencies or malfeasance. Meanwhile, higher trust in informal institutions is disproportionately positively related to higher profits. With respect to infrastructure, we observe that areas with better access to roads, electricity, and water connections exhibit positive associations with profits, but ambiguous associations with employment. Finally, we find mixed evidence with respect to several other general business environment indicators. For example, we do not observe any relationship between stated levels of competition and either business indicator. However, areas with higher average business opportunity and female empowermennt index scores show signs of significantly greater employment and profits, respectively.

The main messages from this discussion are severalfold. First, taking a step back and looking at the bigger picture, enterprise investment and growth has long been considered central to the theories of change linking financial access with poverty alleviation. That is, without some form of transformative effect on business size or profits, the causal chain is cut off early, which reduces the likelihood of finding later effects on poverty indicators. Our results suggest that financial access in isolation is less likely to trigger the desired transformative effects, or may not be meeting its real potential, unless coupled with the right opportunities in the business environment. This requires active roles from both national and subnational governments to foster necessary improvements, wherever possible.

Second, this also means that more attention should be paid to interpreting the results from past microcredit impact evaluations in light of the contextual environments that the respective clients' lived and operated in. Our message is along the lines of Pritchett \& Sandefur (2015), who conclude by noting: "With the enormous benefit of hindsight, this heterogeneity [in the RCT results] is not surprising. After all, the programs and contexts in which they operated differed enormously[... The catchall term "microcredit" encompasses virtually infinite permutations of program characteristics... The bottom line is that policymakers should be extremely cautious in extrapolating the results of impact evaluations across contexts. However, they can go a long why by focusing on nuances and underlying mechanisms, and carefully avoid such extrapolations." 
Contextual predictors of business outcomes from past RCTs

Point estimates and $95 \% \mathrm{Cls}$ from pooled two-sample t-tests

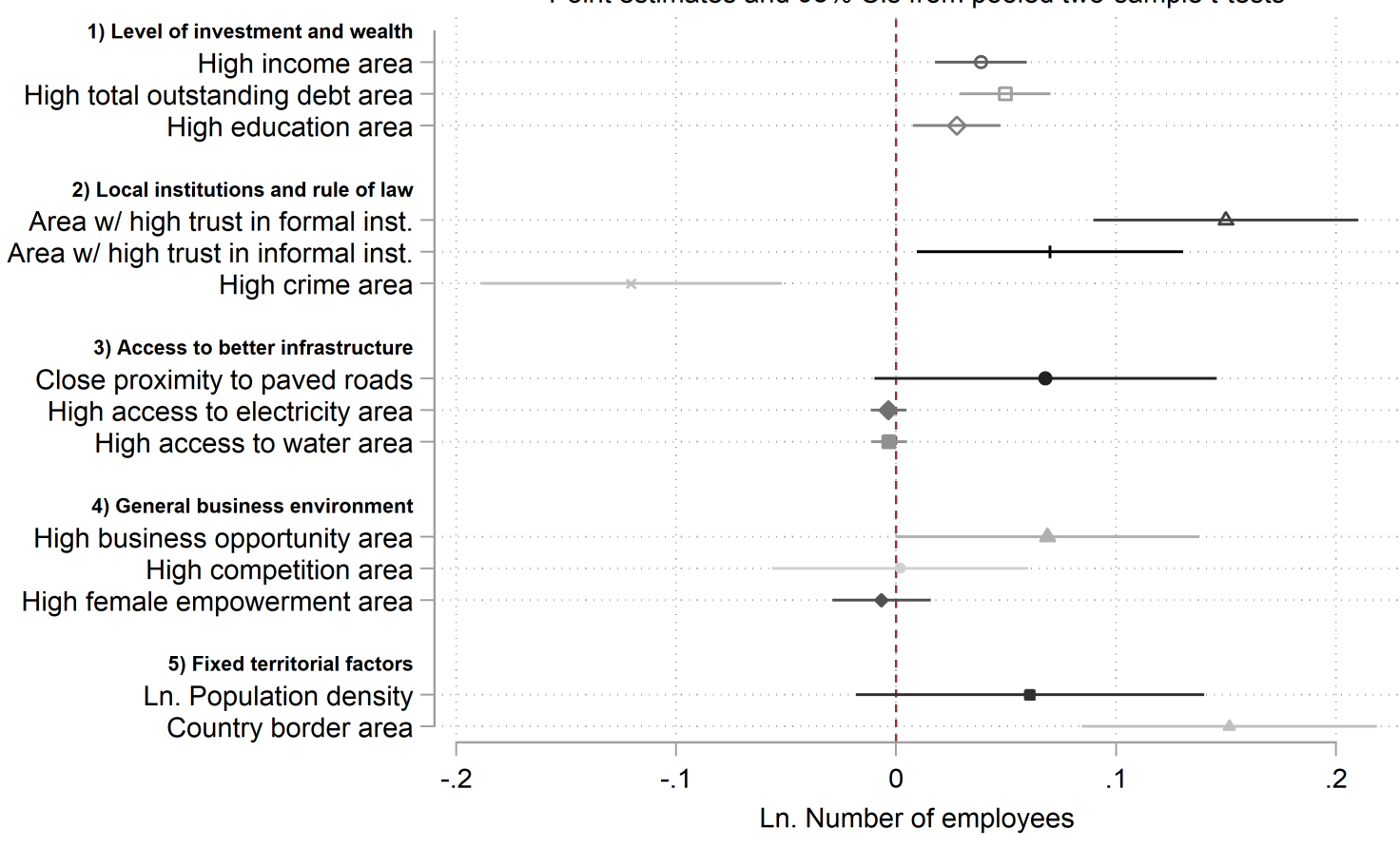

Figure 7: This figure summarizes results from the paper's exploration of business environment factors predicting respondents' business employment in past microcredit impact evaluations. The business employment indicator is a stock value at the time of endline surveys. We identify or construct variables related to the contextual business environment factors highlighted in our study. After standardizing these data, we run t-tests on a null hypothesis that a factor has no significant relationship with employment. Note that 1) the tests are run on the studies' treatment cohorts, since they would be more akin to our sample of micro- and small enterprise clients with access to credit and 2) the studies differ in availability of specific contextual and business outcome variables. For this test, we use data from: (1) Augsburg et al. (2015), (2) Banerjee, Duflo, et al. (2015), (3) Attanasio et al. (2015), (4) Crépon et al. (2015), and (5) Karlan \& Zinman (2011). Appendix Table D.1 provides further details on the study contexts, variables, and outcomes.

In this sense, the paper makes an intuitive but necessary point that the framing of the past RCTs matters. Clients who had both access to credit and better business environments were significantly more likely to exhibit growth that could be considered "transformational". This may paint a different picture concerning the impact of microcredit given ideal conditions. However, it is also important to acknowledge that our results are still in line with existing studies in implying that effects for the average client would remain minimal. Like other studies, we find most evidence that a smaller but important subset of clients drives the majority of business growth. Consequently, this is consistent with other studies suggesting that the promise of microfinance lies less with trying to promote business transformation en masse among the poorest of clients. Rather, as also suggested by Beck (2015), its potential may lie in allowing transformative growth among a select group of small enterprises to supply jobs for others.

Finally, if the ultimate research objective is to eventually be able to accurately predict the impact of some new microcredit program in some new context, then efforts should continue with regards to additional replication studies across more diverse settingscoupled with conscientious data collection in order to capture relevant aspects of those 
Contextual predictors of business outcomes from past RCTs

Point estimates and $95 \% \mathrm{Cls}$ from pooled two-sample t-tests

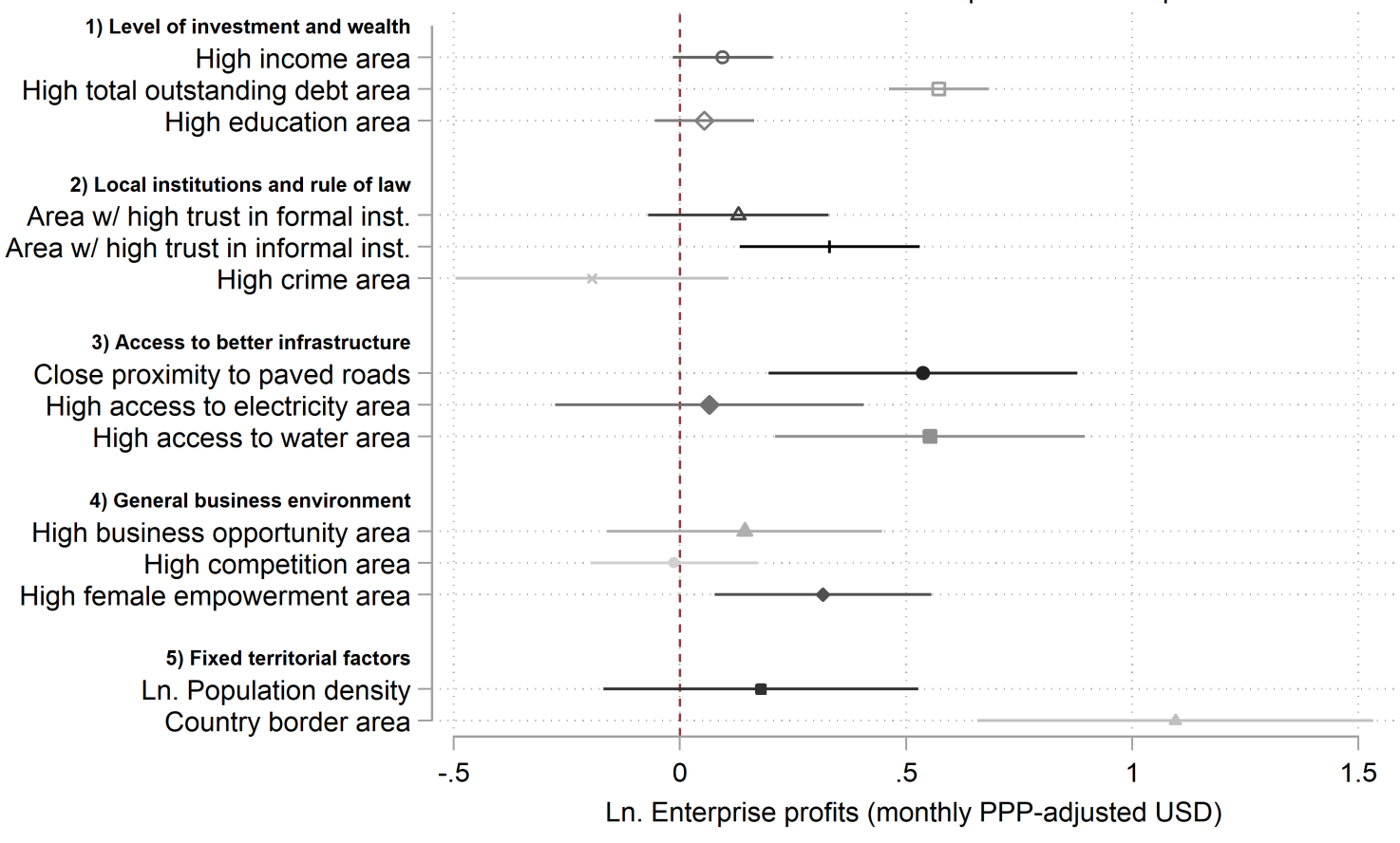

Figure 8: This figure summarizes results from the paper's exploration of business environment factors predicting respondents' business profits in past microcredit impact evaluations. The business profits indicator is standardized as monthly PPP-adjusted USD values as reported at the time of endline surveys. We identify or construct variables related to the contextual business environment factors highlighted in our study. After standardizing these data, we run t-tests on a null hypothesis that a factor has no significant relationship with employment. Note that 1) the tests are run on the studies' treatment cohorts, since they would be more akin to our sample of micro- and small enterprise clients with access to credit and 2) the studies differ in availability of specific contextual and business outcome variables. The data are from: (1) Augsburg et al. (2015), (2) Banerjee, Duflo, et al. (2015), (3) Angelucci et al. (2015), (4) Attanasio et al. (2015), (5) Crépon et al. (2015), and (6) Karlan \& Zinman (2011). Appendix Table D.1 provides further details on the study contexts, variables, and outcomes.

contexts. This can later provide invaluable data to improve our understanding of additional contextual mechanisms that moderate the effects of credit to micro- and small-enterprises and move us closer to that goal. 


\section{Conclusions}

This paper examines the influence of local business environments on micro- and small entrepreneurial growth outcomes using the example of clients of a leading Cambodian microfinance provider. We exploit geographic and temporal variation in the implementation of Cambodia's Special Economic Zones to apply a generalized difference-in-differences model. The SEZs are subject to different laws and regulations relative to other areas of the country and are expected to improve local investment and socioeconomic levels, efficiency of institutions and administrative services, and quality of infrastructure, among other advantages considered conducive to businesses. To establish a valid control group, we estimate the propensity of districts to implement SEZs based on established determinants and then apply inverse propensity score weighting in subsequent counterfactual analyses.

As a main result, we provide evidence that SEZ implementation has positive and economically significant effects on employment growth for micro- and small enterprise clients in SEZ-located districts vis-à-vis similar clients in control districts. Furthermore, we show that a number of client- and district-level factors drawn from related literature are associated with differential effects. Within our study context, employment growth driven by SEZ implementation is particularly pronounced for client businesses that are located in country border districts, higher population density areas, and more mature SEZs. We then decompose the main effect and demonstrate the broader importance of our argument by pooling data from six widely-cited microcredit impact evaluations and using our findings to explore outcome heterogeneity in their results. Results from this secondary analysis confirm the influential role of a number of the aforementioned business environment "framework conditions" in predicting differential outcomes for clients' businesses.

Our findings suggest that the heterogeneity in client outcomes found in key impact studies on microcredit is largely predicted by differences in the clients' subnational and territorial context. This underscores the point that access to credit alone is unlikely to trigger (or meet its true potential on) expected transformative entrepreneurial effects absent proper contextual conditions and suggests caution when broadly extrapolating the past RCT findings across varied study environments. The findings also have practical policy relevance, as they suggest combined or targeted interventions that national and local governments can implement to foster local business environments that are more conducive to achieving some of the desired objectives from financial inclusion.

It is worth clarifying that the external validity of the results is limited to already financially-included enterprises, which may differ from non-financially-included peers. Nevertheless, Cambodia has managed to achieve fairly high market penetration and our research partner is among the leading providers in the country. Consequently, results from the study provide relevant evidence of microfinance client growth outcomes and heterogeneity representing a large and important microfinance market and provider.

It is also important to acknowledge certain limitations of the paper's data and analysis that restrict some of the conclusions that can be drawn. First, the outcome indicators in the paper's primary analysis are limited to two resource-based measures of enterprise growthnamely, absolute and relative growth in terms of number of employees - which reflect the available data in our partner's MIS data. Meanwhile, previous studies in empirical enterprise growth literature have documented weaker correlation between resource-based measures and alternative measures capturing increases in an enterprise's product or service acceptance in the market, such as sales and profits (Wiklund et al., 2009). Nevertheless, 
our secondary analysis on pooled data from prior studies helps demonstrate that many of the highlighted contextual factors are also associated with more dynamic businesses in a number of additional relevant indicators. Second, while we believe the use of districts as the territorial-level unit of analysis is justified based on the research provider's branch structure, our approach possibly underestimates spillover effects between treated and control firms. Finally, while the client data used in this study cover a longer timescale than most previous microfinance impact studies, it is likely they still cover too limited of a timespan to capture the full effects of the introduction of a favorable business environment on financially-included micro- and small enterprises. For example, Farole (2011) makes the important point that the most successful SEZs have often required an incubation period, with "the biggest SEZ success stories including the PRC and Malaysia t[aking] at least 5 to 10 years before they began to build momentum." To the extent that confounding factors are limited in the study areas, repeating the analysis after more time has elapsed could provide informative results. Addressing any or all of these issues would be promising avenues for future research.

\section{References}

Abonyi, G., Zola, A., \& Suwannakarn, E. (2016). The role of special economic zones in improving effectiveness of GMS economic corridors. Asian Development Bank.

Acemoglu, D., Gallego, F. A., \& Robinson, J. A. (2014). Institutions, human capital, and development. Annual Review of Economics, 6(1), 875-912.

Acs, Z. J., \& Mueller, P. (2008). Employment effects of business dynamics: Mice, gazelles and elephants. Small Business Economics, 30(1), 85-100.

Aggarwal, A. (2010). Economic impacts of SEZs: Theoretical approaches and analysis of newly notified SEZs in India. MPRA Working Paper No. 20902.

Akinci, G., \& Crittle, J. (2008). Special economic zones: Performance, lessons learned, and implications for zone development. Washington DC: The World Bank, E3.

Alkon, M. (2018). Do special economic zones induce developmental spillovers? Evidence from India's states. World Development, 107, 396-409.

Alliance for Financial Inclusion. (2019). Maya Declaration Progress Report for 2019: Driving Impact on the Ground. Alliance for Financial Inclusion.

Angelucci, M., Karlan, D., \& Zinman, J. (2015). Microcredit impacts: Evidence from a randomized microcredit program placement experiment by Compartamos Banco. American Economic Journal: Applied Economics, 7(1), 151-182.

Armendáriz, B., \& Morduch, J. (2010). The economics of microfinance. MIT press.

Ashraf, N., Giné, X., \& Karlan, D. (2009). Finding missing markets (and a disturbing epilogue): Evidence from an export crop adoption and marketing intervention in Kenya. American Journal of Agricultural Economics, 91(4), 973-990. 
Asian Development Bank. (2016). Cambodia Economic Update: Improving Macroeconomic and Financial Resilience. World Bank and Asian Development Bank.

Attanasio, O., Augsburg, B., De Haas, R., Fitzsimons, E., \& Harmgart, H. (2015). The impacts of microfinance: Evidence from joint-liability lending in Mongolia. American Economic Journal: Applied Economics, 7(1), 90-122.

Audretsch, D. (2012). Determinants of high-growth entrepreneurship. Report prepared for the OECD. In DBA International Workshop on High-growth firms: local policies and local determinants, Copenhagen (Vol. 28).

Augsburg, B., De Haas, R., Harmgart, H., \& Meghir, C. (2015). The impacts of microcredit: Evidence from Bosnia and Herzegovina. American Economic Journal: Applied Economics, 7(1), 183-203.

Austin, P. C., \& Stuart, E. A. (2015). Moving towards best practice when using inverse probability of treatment weighting (IPTW) using the propensity score to estimate causal treatment effects in observational studies. Statistics in Medicine, 34(28), 3661-3679.

Baissac, C. (2011). Brief history of SEZs and overview of policy debates, [w:] Special Economic Zones in Africa. Comparing performance and learning from global experience. World Bank, Washington.

Banerjee, A. (2013). Microcredit under the microscope: What have we learned in the past two decades, and what do we need to know? Annual Review of Economics, 5(1), 487-519. doi: 10.1146/annurev-economics-082912-110220

Banerjee, A., Duflo, E., Glennerster, R., \& Kinnan, C. (2015). The miracle of microfinance? Evidence from a randomized evaluation. American Economic Journal: Applied Economics, 7(1), 22-53.

Banerjee, A., Karlan, D., \& Zinman, J. (2015). Six randomized evaluations of microcredit: Introduction and further steps. American Economic Journal: Applied Economics, 7(1), $1-21$.

Baumol, W. J. (1996). Entrepreneurship: Productive, unproductive, and destructive. Journal of Business Venturing, 11(1), 3-22.

Beck, T. (2015). Microfinance-a critical literature survey. World Bank Group. IEG working paper(4).

Bjørnskov, C., \& Foss, N. J. (2016). Institutions, entrepreneurship, and economic growth: What do we know and what do we still need to know? Academy of Management Perspectives, 30(3), 292-315.

Bräutigam, D., \& Tang, X. (2014). "Going global in groups": Structural transformation and China's special economic zones overseas. World Development, 63, 78-91.

Bruhn, M. (2013). A tale of two species: Revisiting the effect of registration reform on informal business owners in Mexico. Journal of Development Economics, 103, 275-283.

Bruhn, M., \& Love, I. (2014). The real impact of improved access to finance: Evidence from Mexico. The Journal of Finance, 69(3), 1347-1376. 
Caliendo, M., \& Kopeinig, S. (2008). Some practical guidance for the implementation of propensity score matching. Journal of Economic Surveys, 22(1), 31-72.

Cheesman, A. (2012). Special economic zones \& development: Geography and linkages in the Indian EOU scheme. Development Planning Unit, University College London, Working Paper NO. 145.

Cirera, X., \& Lakshman, R. W. (2017). The impact of export processing zones on employment, wages and labour conditions in developing countries: A systematic review. Journal of Development Effectiveness, 9(3), 344-360.

Ciżkowicz, P., Ciżkowicz-Pękała, M., Pękała, P., \& Rzońca, A. (2016). The effects of special economic zones on employment and investment: A spatial panel modeling perspective. Journal of Economic Geography, 17(3), 571-605.

Coad, A. (2009). The growth of firms: A survey of theories and empirical evidence. Edward Elgar Publishing.

Coad, A., Daunfeldt, S.-O., Hölzl, W., Johansson, D., \& Nightingale, P. (2014). Highgrowth firms: introduction to the special section. Industrial and Corporate Change, $23(1), 91-112$.

Coad, A., \& Rao, R. (2008). Innovation and firm growth in high-tech sectors: A quantile regression approach. Research Policy, 37(4), 633-648.

Cotler, P., \& Woodruff, C. (2008). The impact of short-term credit on microenterprises: Evidence from the Fincomun-Bimbo program in Mexico. Economic Development and Cultural Change, 56(4), 829-849.

Crépon, B., Devoto, F., Duflo, E., \& Parienté, W. (2015). Estimating the impact of microcredit on those who take it up: Evidence from a randomized experiment in Morocco. American Economic Journal: Applied Economics, 7(1), 123-150.

Daunfeldt, S.-O., \& Elert, N. (2013). When is gibrat's law a law? Small Business Economics, 41(1), 133-147.

Daunfeldt, S.-O., Elert, N., \& Johansson, D. (2014). The economic contribution of high-growth firms: Do policy implications depend on the choice of growth indicator? Journal of Industry, Competition and Trade, 14(3), 337-365.

Davidsson, P., Achtenhagen, L., \& Naldi, L. (2010). Small firm growth. Foundations and Trends in Entrepreneurship, 6(2), 69-166.

Deaton, A., \& Cartwright, N. (2018). Understanding and misunderstanding randomized controlled trials. Social Science \& Medicine, 210, 2-21.

De Mel, S., McKenzie, D., \& Woodruff, C. (2014). Business training and female enterprise start-up, growth, and dynamics: Experimental evidence from Sri Lanka. Journal of Development Economics, 106, 199-210.

Demirgüç-Kunt, A., Klapper, L., \& Singer, D. (2017). Financial inclusion and inclusive growth: A review of recent empirical evidence. The World Bank. 
Duvendack, M. (2011). What is the evidence of the impact of microfinance on the wellbeing of poor people? London: EPPI-Centre, Social Science Research Unit, Institute of Education, University of London.

Fajnzylber, P., Maloney, W., \& Rojas, G. M. (2006). Microenterprise dynamics in developing countries: How similar are they to those in the industrialized world? Evidence from Mexico. The World Bank Economic Review, 20(3), 389-419.

Farole, T. (2011). Special economic zones in Africa: Comparing performance and learning from global experiences. World Bank Publications.

Frick, S. A., Rodríguez-Pose, A., \& Wong, M. D. (2018). Toward economically dynamic special economic zones in emerging countries. Economic Geography, 1-35.

Giner, J. M., Santa-María, M. J., \& Fuster, A. (2016). High-growth firms: Does location matter? International Entrepreneurship and Management Journal, 1-22.

Hallward-Driemeier, M., Wallsten, S., \& Xu, L. C. (2006). Ownership, investment climate and firm performance. Economics of Transition, 14(4), 629-647.

Hill, H., \& Menon, J. (2013). Cambodia: Rapid growth with weak institutions. Asian Economic Policy Review, 8(1), 46-65.

Hsieh, C.-T., \& Klenow, P. J. (2009). Misallocation and manufacturing TFP in China and India. The Quarterly Journal of Economics, 124(4), 1403-1448.

Imbens, G. W., \& Rubin, D. B. (2015). Causal inference in statistics, social, and biomedical sciences. Cambridge University Press.

Johansson, H., \& Nilsson, L. (1997). Export processing zones as catalysts. World Development, 25(12), 2115-2128.

Karlan, D., Knight, R., \& Udry, C. (2015). Consulting and capital experiments with microenterprise tailors in Ghana. Journal of Economic Behavior $\mathscr{G}$ Organization, 118, $281-302$.

Karlan, D., \& Valdivia, M. (2011). Teaching entrepreneurship: Impact of business training on microfinance clients and institutions. Review of Economics and statistics, 93(2), $510-527$.

Karlan, D., \& Zinman, J. (2011). Microcredit in theory and practice: Using randomized credit scoring for impact evaluation. Science, 332(6035), 1278-1284.

Klapper, L., \& Richmond, C. (2011). Patterns of business creation, survival and growth: Evidence from Africa. Labour Economics, 18, S32-S44.

Levine, R. (2005). Finance and growth: theory and evidence. Handbook of economic growth, 1, 865-934.

Malesky, E. J. (2009). The Provincial Business Environment Scorecard in Cambodia: A Measure of Economic Governance and Regulatory Policy (Tech. Rep.). Asia Foundation and the International Finance Corporation. 
Martmez, C., \& Krauss, A. (2015). What Drives Financial Inclusion at the Bottom of the Pyramid? Empirical Evidence from Microfinance Panel Data (Tech. Rep.). Centre for Finance and Development, The Graduate Institute, WP No-07.

McKenzie, D., de Mel, S., \& Woodruff, C. (2008). Returns to capital: Results from a randomized experiment. Quarterly Journal of Economics, 123(4), 1329-72.

Mead, D. C., \& Liedholm, C. (1998). The dynamics of micro and small enterprises in developing countries. World Development, 26(1), 61-74.

Meager, R. (2019). Understanding the average impact of microcredit expansions: A bayesian hierarchical analysis of seven randomized experiments. American Economic Journal: Applied Economics, 11(1), 57-91.

Nankhuni, F., \& Paniagua, G. (2013). Meta-evaluation of private sector interventions in agribusiness: Finding out what worked in access to finance and farmer/business training. Washington, DC: IFC.

North, D. C. (1991). Institutions. Journal of Economic Perspectives, 5(1), 97-112.

Open Development Cambodia. (2017). Special economic zones. Retrieved 2017-1-24, from https://opendevelopmentcambodia.net/profiles/special-economic-zones/

Pande, R., Cole, S., Sivasankaran, A., Bastian, G., \& Durlacher, K. (2012). Does poor people's access to formal banking services raise their incomes? London: EPPI-Centre, Social Science Research Unit, Institute of Education, University of London.

Porter, M. E. (1998). Clusters and the new economics of competition (Vol. 76) (No. 6). Harvard Business Review Boston.

Pritchett, L., \& Sandefur, J. (2015). Learning from experiments when context matters. American Economic Review, 105(5), 471-75.

Stam, E. (2009). Entrepreneurship, evolution and geography. Papers on economics and evolution, No. 090\%, Max-Planck-Inst. für Ökonomik, Jena.

Steenbergen, V., \& Javorcik, B. (2017). Analyzing the impact of the Kigali special economic zone on firm behavior (Tech. Rep.). Working Paper F-38419-RWA-1, London School of Economics, International Growth Center.

Tarozzi, A., Desai, J., \& Johnson, K. (2015). The impacts of microcredit: Evidence from Ethiopia. American Economic Journal: Applied Economics, 7(1), 54-89.

Vivalt, E. (2020). How much can we generalize from impact evaluations? Journal of the European Economics Association, Forthcoming.

Wang, J. (2013). The economic impact of special economic zones: Evidence from Chinese municipalities. Journal of Development Economics, 101, 133-147.

Warr, P., \& Menon, J. (2016). Cambodia's special economic zones. Journal of Southeast Asian Economies, 33(3), 273-290.

Wiklund, J., Patzelt, H., \& Shepherd, D. A. (2009). Building an integrative model of small business growth. Small Business Economics, 32(4), 351-374. 
World Bank. (2019). Retrieved 2019-10-12, from https://databank.worldbank.org/ source/world-development-indicators

Wydick, B. (2016). Microfinance on the margin: Why recent impact studies may understate average treatment effects. Journal of Development Effectiveness, 8(2), 257-265. 


\section{Notes}

${ }^{1}$ In drawing this conclusion, Beck $(2015)$ also takes into account a number of recent systematic reviews that have been conducted on the impact of microfinance and microcredit, including those conducted by Duvendack (2011); Nankhuni \& Paniagua (2013); Pande et al. (2012).

2Attanasio et al. (2015); Banerjee, Duflo, et al. (2015) are currently the longest-term studies, with 42 and 43 month follow-ups, respectively. However, they still only accurately capture effects of a one-time intervention.

${ }^{3}$ In the past thirty years, the number of Special Economic Zones worldwide has grown from 176 SEZs in 47 countries in the mid 1980's to 3,500 SEZs in 130 countries as of 2008 (Farole, 2011).

4 Akinci \& Crittle (2008) attempt to estimate the indirect employment effects of SEZs and note that it may be quite substantial in some cases, with a ratio of indirect to direct jobs created ranging from 0.25 percent in Mauritius, to 0.7 percent in Madagascar, to 2.0 in Honduras. They estimate that the indirect employment effect of SEZ development globally could range from 9.6 million to 77 million jobs and that zones can and do play a major role in employment creation in certain countries. Meanwhile, it is important to acknowledge that other case studies on dynamic effects from SEZs in other settings have turned up inconclusive or negative results. For example, several have noted that there has been a general lack of dynamic effects of SEZs set up in Latin American and Sub-Saharan African countries (Bräutigam \& Tang, 2014, Farole, 2011).

Cirera \& Lakshman (2017) conduct a comprehensive systematic review of 59 studies to synthesize the empirical evidence in relation to the impact of SEZs on employment, wages, and labour conditions in developing countries, and find that a select number of studies establish some degree of attribution between SEZs and outcomes through the use of proper comparison groups. However, a review of the relevant studies included demonstrate that these are largely measuring direct employment in SEZ firms, rather than outside firms that would be beneficiaries of linkage and spillover effects.

${ }^{6}$ Cambodia experienced a brief but sharp economic contraction prior to our study period between the third quarter of 2008 to the first quarter of 2009 caused by the Global Financial Crisis. During the crisis, GDP growth fell to as low as 0.1 percent, inflation reached a decade-high level of 35.57 percent, and there was a substantial loss of formal jobs in the garment and construction industries. However, by the end of 2010, GDP growth returned to 6 percent, inflation levels fell to near zero percent annual real growth, and demand in the affected economic sectors had picked up enough that employers had hired back most workers en masse.

${ }^{7}$ For example, the SEZs have had an initial capitalization of over 2 billion USD by initial owners alone (Open Development Cambodia, 2017).

${ }^{8}$ Furthermore, Warr \& Menon (2016)'s surveys on SEZ-located firms reveal that employment conditions, including average wages, are considered quite good by Cambodian standards.

${ }^{9}$ See Appendix section A for details on the sample design and methodology of extraction.

${ }^{10}$ The sample excludes the provider's medium-sized enterprises and group loans. The provider's annual reports indicate that these types of loans comprise a small portion of their loan portfolio in terms of numbers of clients - ranging from four to five percent of their clients between 2011 and 2016, albeit comprising a larger percentage in terms of loan volume.

${ }^{11}$ It is worth mentioning that we also explore growth in client assets as a possible dependent variable. However, the variable is more ambiguous in the sense that it encompasses a client's combined assets- that is, both household and business. As such, it may not be necessarily a direct measure of changes in a clients business per se, particularly for small enterprises, who are more likely to have separated assets. Consequently, we ultimately decide to focus on employment size since it is a direct and unambiguous proxy for business growth.

${ }^{12}$ Daunfeldt et al. (2014) demonstrate that high-growth firms defined by relative growth tend to be smaller than those that are fast growing in absolute terms, suggesting that measures of absolute growth are biased toward larger firms, and vice versa.

${ }^{13}$ The choice of this threshold takes into consideration that the average time between loan applications for clients in our sample is just under a year (see Table E.3). To investigate whether the main results are indeed sensitive to the growth period, we also construct the main dependent variables restricting to observations where just 6 months have passed and normalize them as semesterly growth rates in the Online Appendix.

${ }^{14}$ https://opendevelopmentcambodia.net/profiles/special-economic-zones/

${ }^{15}$ Data obtained from: http://celade.cepal.org/redkhm/census/khm1998/

${ }^{16}$ Data obtained from: http://celade.cepal.org/redkhm/census/khm2008/ 
${ }^{17}$ Cambodia has four tiers of administrative divisions: 1) 24 provinces and the special administrative unit Phnom Penh (25 de facto provinces); 2) 171 districts; 3) 1,621 communes; and 4) 14,073 villages (as of the 2008 census).

${ }^{18}$ This is driven by the expectation that the employment growth trends in the districts with SEZs implemented prior to the start of our study period may already have different - and arguably more positive-business growth trends than the rest of the sample due to the implementation. To explore this, we also run the main models including all twenty branches and provide results in the Online Appendix

${ }^{19}$ The common support or overlap condition rules out the phenomenon of perfect predictability of treatment given $\mathrm{X}$ : (Overlap) $0<\mathrm{P}(\mathrm{D}=1 \mathrm{jX})<1$. It ensures that observations with the same $\mathrm{X}$ values have a positive probability of being both participants and non-participants (Caliendo \& Kopeinig, 2008).

${ }^{20}$ We apply Hedge's $g$ statistic because it has better properties when the sample sizes between the treatment and control groups differ significantly. In practice, it weights each group's standard deviation by its sample size before estimating the full sample population's pooled standard deviation.

${ }^{21}$ It is worth noting that although there is no universally agreed upon criterion as to what threshold of the standardized difference can be used to indicate important imbalance, others have noted that since the standardized difference is a version of Cohen's $d$ statistic for effect size, one could also argue for a cut-off of 0.20 , which Cohen termed a 'small' effect. Austin \& Stuart (2015) also notes the lack of consensus as to what value of a standardized difference can be taken to indicate the presence of meaningful confounding, but at its most stringent criteria, some authors consider any standardized differences below 0.10 this threshold as indicative of a negligible imbalance.

${ }^{22}$ These stylized facts have been found to be fairly robust across enterprises of different sizes and across both developing and developed countries.

${ }^{23}$ Histograms of absolute and relative employee growth for clients in the treatment and control groups show a skewed Laplace distribution, where the top and bottom tails of the distribution account for the majority of business expansion and contraction, respectively, and the larger majority of the clients exhibit no change. This is consistent with enterprise growth literature.

${ }^{24}$ It is worth noting that this is no longer representative of the national sample, but a re-weighted sample which emphasizes the branches and clients in the treatment and control districts.

${ }^{25}$ Note, we have also run the event study and main regression models using annual blocks and results are consistent. For exposition, we choose to use the semesterly blocks as it is more rigorous and allows us to explore the trends more precisely.

${ }^{26}$ The results from these sensitivity tests can be made available in a separate online appendix by request to the corresponding author.

${ }^{27}$ Furthermore, a stylized fact in enterprise growth literature concerns the random nature of business growth and low predictive power of most regression models. In explorative regression models provided in the Online Appendix, we demonstrate that individual business-level characteristics typically are less useful at explaining employment growth than broader district-level characteristics.

${ }^{28}$ Banerjee, Duflo, et al. (2015) goes the furthest in highlighting particular client-level characteristics driving differential effects. For example, they find most of the strong improvements in business outcomes come from households with pre-existing businesses rather than those who start new businesses. Conversely, they find that females in their study cohort had systematically lower business outcomes, citing possibility of gender barriers, etc.

${ }^{29}$ The combined data yield 35,342 observations, of which 18,979 are treatment observations used for the analysis. They cover 285 country subregions. These are typically at the branch level.

${ }^{30}$ All studies measured business outcomes in terms of expenses, revenues and profits. All studies except Mexico measure business outcomes in terms of employment. The studies captured expenses, revenues, and profits as average estimates for different time periods. We standardize these variables as monthly estimates. Furthermore, most studies captured monetary values in terms of local currency units. To make these comparable, we draw on the World Bank's World Development Indicator database to convert all values to PPP adjusted USD at the date of each study's respective baseline survey date. Note that we have also run the same analyses using average annualized exchange rates and results remain fundamentally unchanged.

${ }^{31}$ To operationalize these business environment variables in a way that is easily interpreted and intuitive, we calculate country subregional averages. We then construct dummy variables that flag country subregions that are in the top tercile with respect to a given business environment factor.

${ }^{32}$ Only one study (Mongolia) had disaggregated data on population density readily available. Our original intention was to construct an urban versus rural dummy indicator to be parallel with our own study. However, literature review and data investigation revealed that none of the areas met Mongolia's 
thresholds to be classified as an urban area - that is, all study areas were rural. Thus, we test the general intuition by including (ln.) population density as a continuous variable. To construct a dummy variable for flagging country border areas, we are able to map municipality-level areas for Bosnia and Mongolia to identify which are situated on country borders versus on the interior. This is not applicable for the other countries, as the study areas are either all situated in interior regions (India, Philippines), all situated on the border (Mexico), or not identifiable in the data (Morocco).

${ }^{33} \mathrm{We}$ also provide the comparable figures reporting results for business expenses and revenues in the paper's appendix. Tabular results can be made available by authors. 


\section{A Appendix: Sample design and methodology}

The sample selection and extraction was conducted using the following criteria and steps. First, a target population was defined as any client with their first business loan initiated between January 1st, 2011 and December 31st, 2014. The extracted loan records for any sampled clients cover the period from January 1st, 2011 to December 31st, 2016. Second, from this target population, clients from the research partner's MIS were then randomly selected. Third, a unique customer identifier was used to link all loan records (cycles) for the sampled clients for extraction. Finally, the data were pooled and transformed into an unbalanced panel dataset at the client-loan level for the study's empirical analysis.

\section{B Appendix: Data \& Constructed Variables}

\section{B.1 Data on Business Growth Indicators}

The research partner's management information system (MIS) includes a variable capturing the number of employees for a given client's business at the time of each loan application. We turn the dataset into an unbalanced panel at the client-loan level and calculate the change in employment between loan cycles for each client. Following the literature, we calculate this both in terms of absolute growth and in logarithmic form to capture relative growth. Since the dataset is an unbalanced panel (and there may be different lengths of time between consecutive loan observations), the time unit of the growth measure is normalized into an annual growth rate by dividing the relative change between consecutive loans by the amount of time between the application dates of the loan cycles. Furthermore, to reduce the chance that annualized rates may exaggerate growth if two consecutive loans for a client were somehow received within a short time period, we apply an additional criteria that a minimum of 12 months must pass between consecutive loans for the associated growth observation to be included in the data sample. This is in line with standards from the empirical growth literature, where studies typically calculate growth rates over a minimum period of one year in order to reduce statistical noise and to better account for one-off expansions (Davidsson et al., 2010).

\section{B.2 Data on SEZs}

The paper's main explanatory variable is a dummy indicator constructed at the branch district and time period-level which equals 1 if there is an SEZ implemented in a district in a time period and 0 otherwise. The underlying information for its construction is a database maintained by Open Development Cambodia (ODC) which can be found here: https://opendevelopmentcambodia.net/profiles/special-economic-zones/. This dummy indicator is then mapped to the MIS file at the branch district and time period-level. In other words, it denotes whether a client in a given branch and time period was in a district location with an implemented SEZ. The ODC data also provides the amount of starting capital and the land area of each SEZ.

We construct several additional variables to provide further context on the SEZs. First, we use an administrative map of Cambodia to construct a dummy indicator for whether the district of a given SEZ is located on an ocean border or on a country border. Source: WWW.stat.go.jp/info/meetings/cambodia/pdf/00dis_mp.pdf 
Second, we use a map from the Greater Mekong Subregion Information Portal to construct a dummy indicator for whether a given district is on the Central, Southern, or Southern Coastal GMS corridors. Source: http://portal.gms-eoc.org/maps $?$ cmbIndicatorMapType=archive\&cmbIndicatorTheme=29\&cmbIndicatorMap $=24$

\section{B.3 Data on District Context}

Data on contextual characteristics of districts are drawn from 1998 and 2008 Cambodian General Population Surveys, which were conducted by the Cambodian National Institute of Statistics. These data are available at: http://celade.cepal.org/redkhm/ census/khm1998/ and http://celade.cepal.org/redkhm/census/khm2008/. We use these sources to obtain information on district population size, population growth rate, land area in square kilometers, and population density. With the exception of population growth, which relies on calculating annualized change from 1998, the figures used in the paper are from the 2008 census, which should provide a fairly accurate depiction of district characteristics at the start of our study period, 2011.

\section{B.4 Data for Control Variables}

Data for the client and business-level controls used in the paper's analysis are drawn from the MIS sample. It is also worth mentioning that to facilitate interpretation of monetary figures, any values in Cambodian Riel-for example, loan amount, initial assets, etc.-are converted into USD using the average annual exchange rates for the year of a given loan application, and these values are then adjusted for inflation (that is, deflated) to 2011 levels. The main control variables include:

- Female: a dummy indicator for whether a client is female $=1$ or male $=0$.

- Dependents: a dummy indicator for whether a client is married $=1$ or single $=0$.

- Age: based on the age distribution in the data sample, we create indicators for whether clients fall into the following age brackets: aged under or equal to 30, aged 31 to 40 , aged 41 to 50, and aged over 50. These are calculated based on the client's date of birth and with respect to the time of a given loan application.

- Economic_sector: the MIS data contains a variable which captures more than 150 types of business activities. We use this information to aggregate the business activities into 5 broader categories Agriculture, Service, Trade, Production, and Other, which represent dummy indicators set equal to 1 for when a client's business activity falls into a given category; 0 otherwise.

- Multiple_activities: to capture whether a client engaged in multiple types of business activities, we further construct a dummy indicator for whether a given client's Economic_sector ever changes across loans during the study period. (Data exploration reveals that between 15 to 20 percent of clients took out loans which are in different economic sectors altogether.)

- Small_enterprise: a dummy indicator for whether a client's business is classified as a small business $=1$ or a micro business $=0$ at the time of their first loan cycle with the research partner. It is worth highlighting that this is taken directly from an existing 
MIS variable and follows the research partner's categorization of their clients based on their loan categories. Micro business loans range up to USD 2,500 / 10 million Cambodian Riel and small business loans range from USD 2,500 to 30,000 / 10 million to 120 million Cambodian Riel. This may differ from categorization of micro versus small enterprises applied by other sources. For example, an IFC classification scheme categorizes micro enterprises as those with less than 10 employees or less than USD 50,000 in total assets and small enterprises as those with between 11 to 50 employees and USD 50,000 to 250,000 in total assets, however, it arguably makes sense to apply the criteria of local providers who should best reflect local context.

- First_loan_cycle: the MIS has a variable which captures the loan cycle number for a given client. We use this to construct a dummy variable for whether a given client-loan observation is a first loan cycle $(=1)$ or a subsequent loan cycle $(=0)$. It thus captures whether a client is on the extensive or intensive margin at the time of a given loan initiation. It may also serve as a rough proxy for capturing the life cycle stage of a client's business - that is, younger or more mature businesses. 


\section{Appendix: Overview of Special Economic Zones}

\section{Table C.1: List of Cambodian Special Economic Zones (2002-2016)}

This table lists all of the Special Economic Zones opened in Cambodia until the end of 2016. It provides the SEZs' name, operational start date, district, and province. A '*' denotes an SEZ established in the district during our main study period. Meanwhile, a '**, denotes there was a prior SEZ established in the district before 2011. To avoid confounding effects from the previous SEZ zone, these respective district branches are omitted from the sample for the paper's main empirical analysis. The underlying information for its construction is a database maintained by Open Development Cambodia, found here: https://opendevelopmentcambodia.net/profiles/special-economic-zones/.

\begin{tabular}{|c|c|c|c|c|}
\hline$\#$ & Name of SEZ & Start date & District & Province \\
\hline 1 & Suoy Chheng SEZ & $11 / 26 / 2002$ & Mondol Seima & Koh Kong \\
\hline 2 & S.N.C SEZ & $11 / 26 / 2002$ & Prey Nob & Preah Sihanouk \\
\hline 3 & Stung Hav SEZ & $2 / 18 / 2005$ & Stueng Hav & Preah Sihanouk \\
\hline 4 & N.L.C SEZ & $7 / 15 / 2005$ & Svay Teab & Svay Rieng \\
\hline 5 & Phnom Penh SEZ & $2 / 20 / 2006$ & Posenchey & Phnom Penh \\
\hline 6 & Poi Pet O'Neang SEZ & $10 / 7 / 2005$ & Ou Chrov & Banteay Meanchey \\
\hline 7 & Sihanoukville SEZ 1 & $10 / 25 / 2006$ & Stueng Hav & Preah Sihanouk \\
\hline 8 & Manhattan (Svay Reing) SEZ & $8 / 28 / 2005$ & Chantrea & Svay Rieng \\
\hline 9 & Oknha Mong SEZ & $1 / 4 / 2007$ & Srae Ambel & Koh Kong \\
\hline 10 & Kampot SEZ & $5 / 23 / 2006$ & Kampot & Kampot \\
\hline 11 & Tai Seng Bavet SEZ & $1 / 4 / 2007$ & Chantrea & Svay Rieng \\
\hline 12 & Goldfame Pak Shun SEZ & $1 / 4 / 2007$ & Saang & Kandal \\
\hline 13 & Thary Kampong Cham SEZ & $6 / 11 / 2007$ & Memot & Kampong Cham \\
\hline 14 & Neang Kok Koh Kong SEZ & $10 / 26 / 2007$ & Mondol Seima & Koh Kong \\
\hline 15 & D\&M Bavet SEZ & $11 / 1 / 2007$ & Chantrea & Svay Rieng \\
\hline 16 & Sihanoukville SEZ 2 & $9 / 5 / 2007$ & Prey Nob & Preah Sihanouk \\
\hline 17 & Kiri Sakor Koh Kong SEZ & $12 / 25 / 2007$ & Kiri Sakor & Koh Kong \\
\hline 18 & Kampong Saom SEZ & $1 / 6 / 2009$ & Stueng Hav & Preah Sihanouk \\
\hline 19 & $\mathrm{P}(\mathrm{SEZ}) \mathrm{I} \mathrm{C}$ & $1 / 6 / 2009$ & Svay Teab & Svay Rieng \\
\hline 20 & Sihanoukville Port SEZ & $2 / 8 / 2008$ & Preah Sihanouk & Preah Sihanouk \\
\hline 21 & MDS Thmorda SEZ & $9 / 30 / 2010$ & Veal Veaeng & Pursat \\
\hline 22 & KANDAL S.E.Z* & $6 / 4 / 2012$ & Khsach Kandal & Kandal \\
\hline 23 & H.K.T S.E.Z** & $8 / 15 / 2012$ & Prey Nob & Preah Sihanouk \\
\hline 24 & Dragon King Bavet SEZ* & $8 / 16 / 2012$ & Bavet & Svay Rieng \\
\hline 25 & RATANA SEZ** & $1 / 16 / 2013$ & Srae Ambel & Koh Kong \\
\hline 26 & Try Pheap Ou Ya Dav SEZ* & $4 / 19 / 2013$ & Ou Ya Dav & Ratanak Kiri \\
\hline 27 & Hi-Park SEZ* & $1 / 16 / 2013$ & Bavet & Svay Rieng \\
\hline 28 & Shandong Sunshell SEZ* & $3 / 27 / 2013$ & Bavet & Svay Rieng \\
\hline 29 & Zhong Jian Jin Bian SEZ* & $4 / 19 / 2013$ & Kampong Tralach & Kampong Chhnang \\
\hline 30 & Sanco Cambo SEZ* & $5 / 3 / 2013$ & Poi Pet & Banteay Meanchey \\
\hline 31 & Doung Chhiv Phnom Den SEZ* & $2 / 01 / 2014$ & Kiri Vong & Takeo \\
\hline 32 & Sovannaphum SEZ* & $2 / 11 / 2014$ & Kien Svay & Kandal \\
\hline 33 & Svay Rieng GIGA SEZ** & $7 / 24 / 2014$ & Svay Teab & Svay Rieng \\
\hline 34 & Chhak Kampongsaom SEZ** & $3 / 29 / 2016$ & Srae Ambel & Koh Kong \\
\hline 35 & UBE Snoul SEZ* & $6 / 24 / 2016$ & Snuol & Kratie \\
\hline 36 & Tian Rui Agricultural Trade SEZ* & $6 / 24 / 2016$ & Kong Pisei & Kampong Speu \\
\hline
\end{tabular}




\section{Appendix: Summary of microcredit RCT datasets used for secondary analysis}

Table D.1: Overview of study contexts and available data on territorial-level context, and entrepreneurial outcomes

This table summarizes key impact evaluations assessing the effects of microcredit. It adapts Tables 1 and 2 of Banerjee, Karlan, \& Zinman (2015). We describe relevant aspects of the studies' contexts and evidence of product take-up, business creation, and business growth. The territorial-level business environment variables are used for our analysis and either directly available through the study data or constructed using the primary data. We focus on the following studies as they are considered of high quality, are widely-cited, and have provided publicly-available data, allowing us to explore the role of relevant contextual factors in explaining heterogeneity in results. The studies are: (1) Augsburg et al. (2015), (2) Banerjee, Duflo, et al. (2015), (3) Angelucci et al. (2015), (4) Attanasio et al. (2015), (5) Crépon et al. (2015), and (6) Karlan \& Zinman (2011).

\begin{tabular}{|c|c|c|c|c|c|c|}
\hline Study: & $\begin{array}{l}\text { Bosnia \& Herzegovina } \\
\text { (1) }\end{array}$ & $\begin{array}{l}\text { India } \\
(2)\end{array}$ & $\begin{array}{l}\text { Mexico } \\
\text { (3) }\end{array}$ & $\begin{array}{l}\text { Mongolia } \\
\text { (4) }\end{array}$ & $\begin{array}{l}\text { Morocco } \\
(5)\end{array}$ & $\begin{array}{l}\text { Philippines } \\
\text { (6) }\end{array}$ \\
\hline \multicolumn{7}{|c|}{ Panel A. Country and study context } \\
\hline $\begin{array}{ll}\text { Country GDP } & \text { per } \\
\text { capita (PPP USD) }\end{array}$ & $\$ 8,431$ & $\$ 3,662$ & $\$ 14,667$ & $\$ 6,109$ & $\$ 5,455$ & $\$ 1,800$ \\
\hline Region of study & 14 regions nationwide & $\begin{array}{l}1 \text { major metropolitan } \\
\text { area (Hyderabad) }\end{array}$ & $\begin{array}{l}4 \text { regions in North- } \\
\text { Central Sonora }\end{array}$ & 5 Northern regions & $\begin{array}{l}11 \text { regions throughout } \\
\text { country }\end{array}$ & $\begin{array}{l}\text { Provinces of Rizal, } \\
\text { Cavite, \& Metro Manila }\end{array}$ \\
\hline Location types & $\begin{array}{l}\text { Urban, Peri-urban, Ru- } \\
\text { ral }\end{array}$ & Urban, Peri-urban & $\begin{array}{l}\text { Urban, Peri-urban, Ru- } \\
\text { ral }\end{array}$ & Rural & Peri-urban & $\begin{array}{l}\text { Urban, Peri-urban, Ru- } \\
\text { ral }\end{array}$ \\
\hline $\begin{array}{l}\text { High outcome hetero- } \\
\text { geneity found by au- } \\
\text { thors? }\end{array}$ & Yes & Yes & $\begin{array}{l}\text { Yes, authors note pre- } \\
\text { existing businesses drive } \\
\text { results on growth }\end{array}$ & $\begin{array}{l}\text { Yes, most increase in } \\
\text { bus. ownership among } \\
\text { lower-educated clients }\end{array}$ & $\begin{array}{l}\text { Yes, authors note pre- } \\
\text { existing business drive } \\
\text { results on growth }\end{array}$ & Not reported \\
\hline
\end{tabular}

Panel B. Territorial-level context at baseline (variables available $(Y / N)$ ?) $\dagger$

High income area

High hh. debt area

High education area

Area w/ high trust in

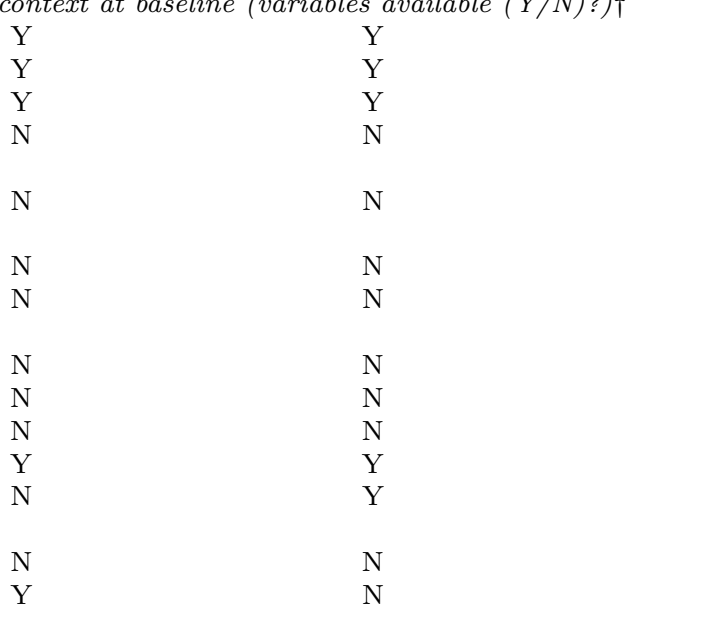

$\mathrm{Y}$
$\mathrm{Y}$
$\mathrm{Y}$
$\mathrm{Y}$
$\mathrm{Y}$
$\mathrm{N}$
$\mathrm{N}$
$\mathrm{N}$
$\mathrm{N}$
$\mathrm{N}$
$\mathrm{N}$
$\mathrm{N}$
$\mathrm{N}$
$\mathrm{Y}$

formal institutions

Area w/ high trust in in-

formal institution

High crime area

paved roads

Access to electricity

Access to (piped) wate

High opportunity area

High competition area

High female empower-

ment area

Population density

Country border and in-

terior regions 
Table D.1 - Continued from previous page

\begin{tabular}{|c|c|c|c|c|c|c|}
\hline Study: & $\begin{array}{l}\text { Bosnia \& Herzegovina } \\
\text { (1) }\end{array}$ & $\begin{array}{l}\text { India } \\
(2)\end{array}$ & $\begin{array}{l}\text { Mexico } \\
(3)\end{array}$ & $\begin{array}{l}\text { Mongolia } \\
(4)\end{array}$ & $\begin{array}{l}\text { Morocco } \\
(5)\end{array}$ & $\begin{array}{l}\text { Philippines } \\
(6)\end{array}$ \\
\hline \multicolumn{7}{|c|}{ Panel C. Client-level context } \\
\hline Gender of client & Male, Female & Female only & Female only & Female only & Male, Female & Male, Female \\
\hline $\begin{array}{l}\text { Prior business owner- } \\
\text { ship }\end{array}$ & $51 \%$ at baseline & $7 \%$ & $21 \%$ & $61 \%$ at baseline & & \\
\hline $\begin{array}{l}\text { Main economic activi- } \\
\text { ties }\end{array}$ & $\begin{array}{l}38 \% \text { agriculture, } 33 \% \\
\text { production or trade, and } \\
29 \% \text { services }\end{array}$ & $\begin{array}{l}24 \% \text { agriculture, } 19 \% \\
\text { production or trade, } \\
17 \% \text { services, and } 40 \% \\
\text { other }\end{array}$ & $\begin{array}{l}\text { Not described or cap- } \\
\text { tured in data }\end{array}$ & $\begin{array}{l}34 \% \text { agriculture or ani- } \\
\text { mal husbandry, } 37 \% \text { pro- } \\
\text { duction or trade, } 14 \% \\
\text { services, } 14 \% \text { other }\end{array}$ & $\begin{array}{l}80-85 \% \text { Animal hus- } \\
\text { bandry and agriculture, } \\
15-20 \% \text { of non-farm busi- } \\
\text { ness }\end{array}$ & $\begin{array}{l}0 \% \text { agriculture, } 18 \% \text { pro- } \\
\text { duction or trade, } 82 \% \\
\text { services. }\end{array}$ \\
\hline \multicolumn{7}{|c|}{ Panel D. Business outcomes (variables available $(Y / N)$ ?) } \\
\hline \# of employees & $\mathrm{Y}$ & $\mathrm{Y}$ & $\mathrm{N}$ & $\mathrm{Y}$ & $\mathrm{Y}$ & Y \\
\hline Revenue & $\mathrm{Y}$ & $\mathrm{Y}$ & $\mathrm{Y}$ & $\mathrm{Y}$ & $\mathrm{Y}$ & $\mathrm{Y}$ \\
\hline Expenses & $\mathrm{Y}$ & $\mathrm{Y}$ & $\mathrm{Y}$ & $\mathrm{Y}$ & $\mathrm{Y}$ & Y \\
\hline Profits & $\mathrm{Y}$ & $\mathrm{Y}$ & $\mathrm{Y}$ & $\mathrm{Y}$ & $\mathrm{Y}$ & $\mathrm{Y}$ \\
\hline Assets & $\mathrm{N}$ & $\mathrm{Y}$ & $\mathrm{Y}$ & $\mathrm{N}$ & $\mathrm{Y}$ & $\mathrm{Y}$ \\
\hline Investment & $\mathrm{N}$ & $\mathrm{Y}$ & $\mathrm{N}$ & $\mathrm{N}$ & $\mathrm{Y}$ & $\mathrm{N}$ \\
\hline
\end{tabular}

